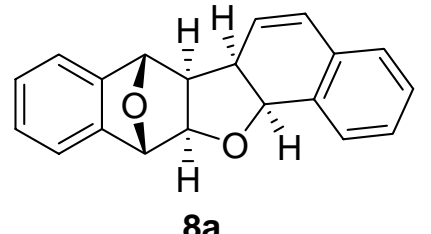

(Table 7 , entry 1 )

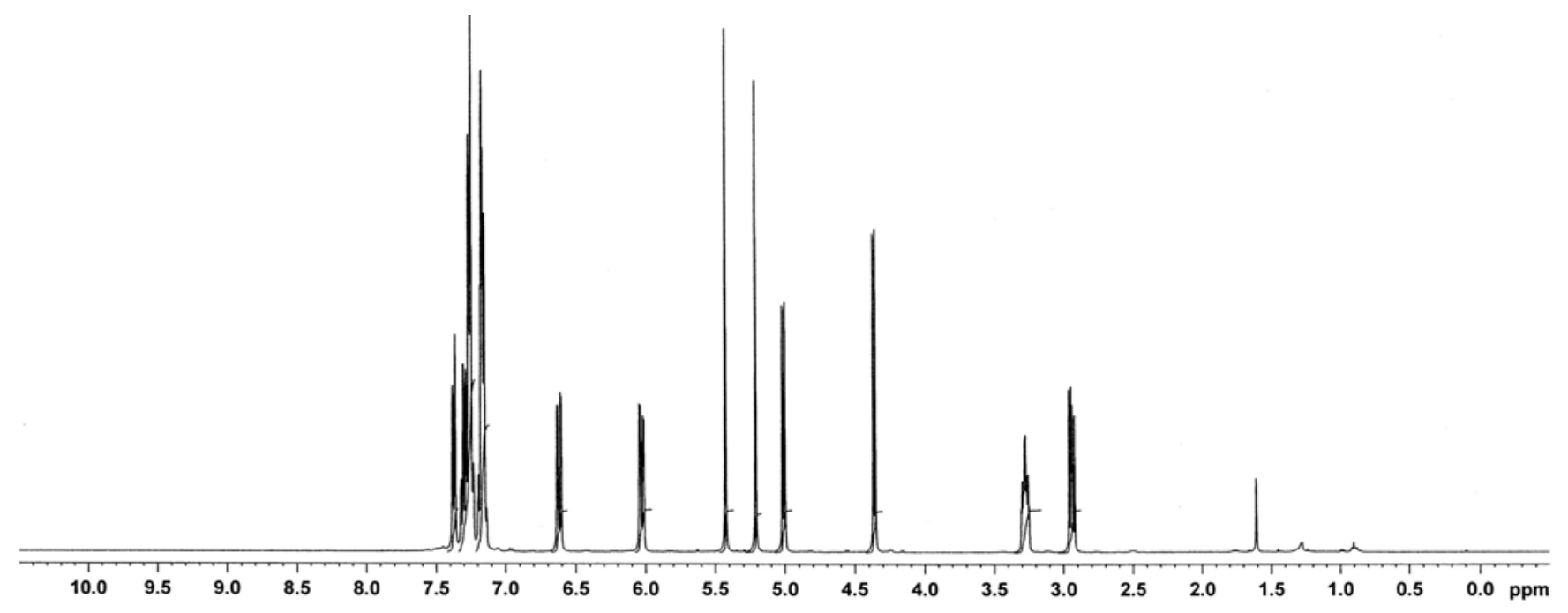

(400 $\mathrm{MHz}^{1} \mathrm{H}$ NMR spectrum, $\mathrm{CDCl}_{3}$ )

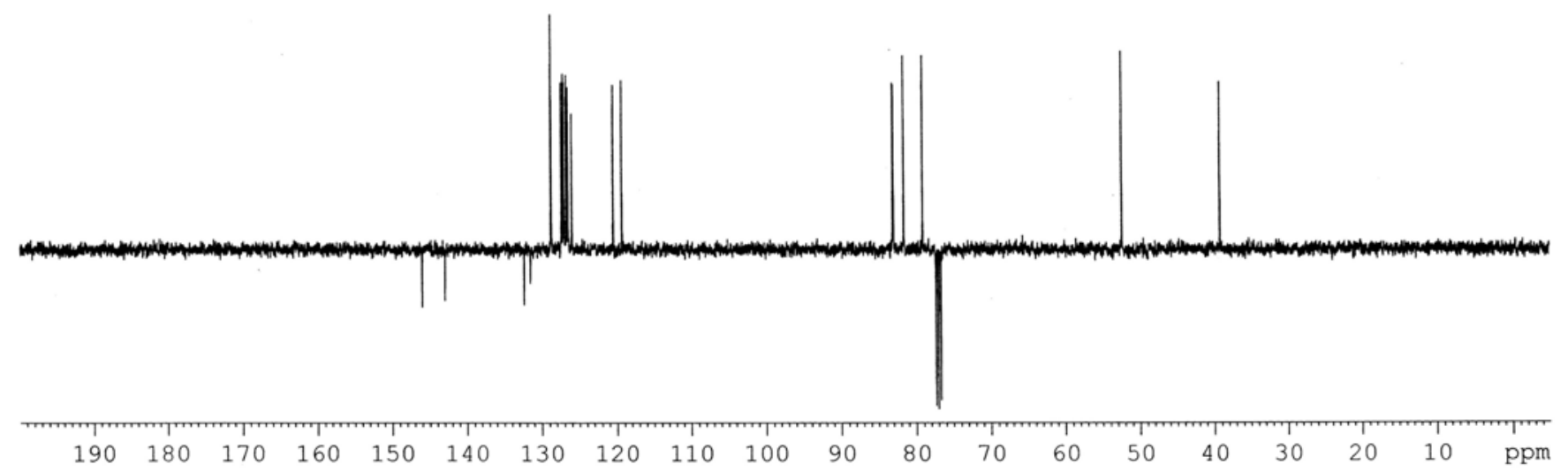

$\left(100 \mathrm{MHz}^{13} \mathrm{C}\right.$-APT NMR spectrum, $\mathrm{CDCl}_{3}$ ) 


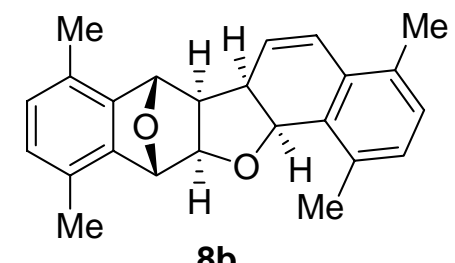

(Table 7, entry 2)

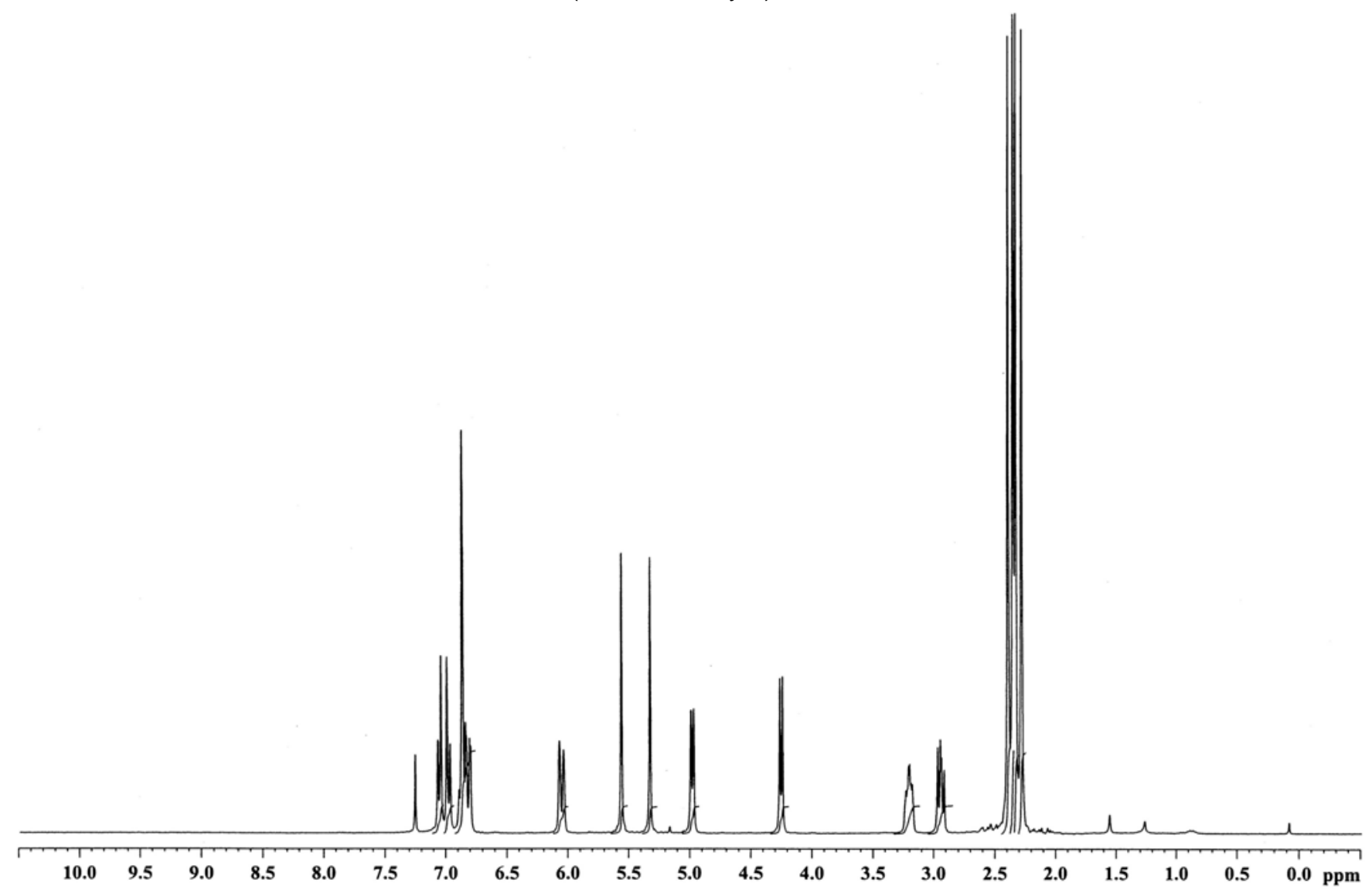

(300 $\mathrm{MHz}{ }^{1} \mathrm{H}$ NMR spectrum, $\mathrm{CDCl}_{3}$ )

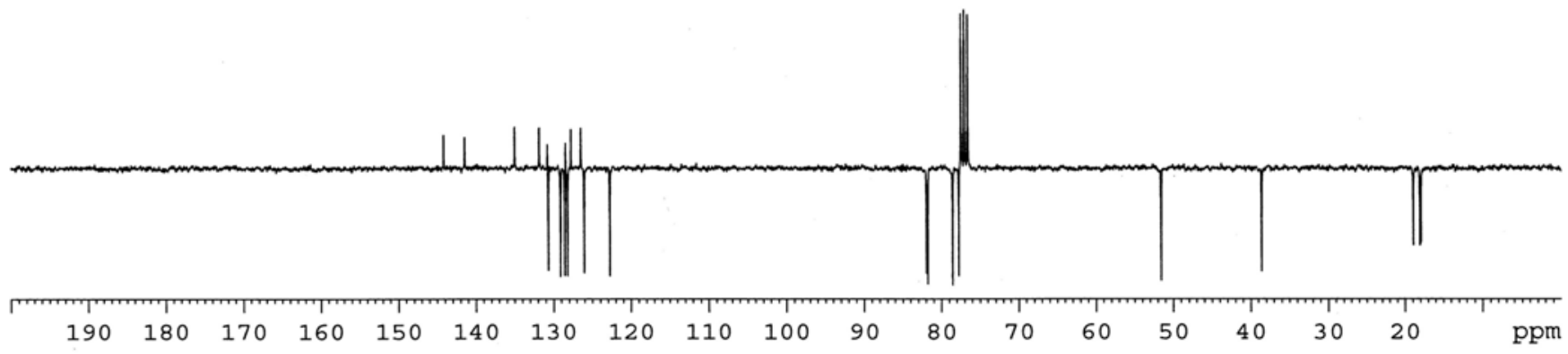

(75 $\mathrm{MHz}^{13} \mathrm{C}$-APT NMR spectrum, $\mathrm{CDCl}_{3}$ ) 


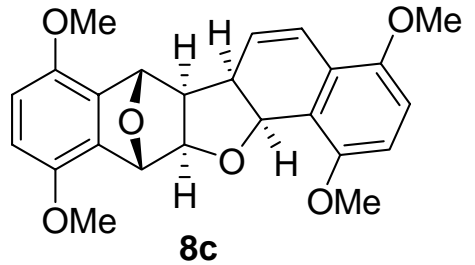

(Table 7, entry 3 )

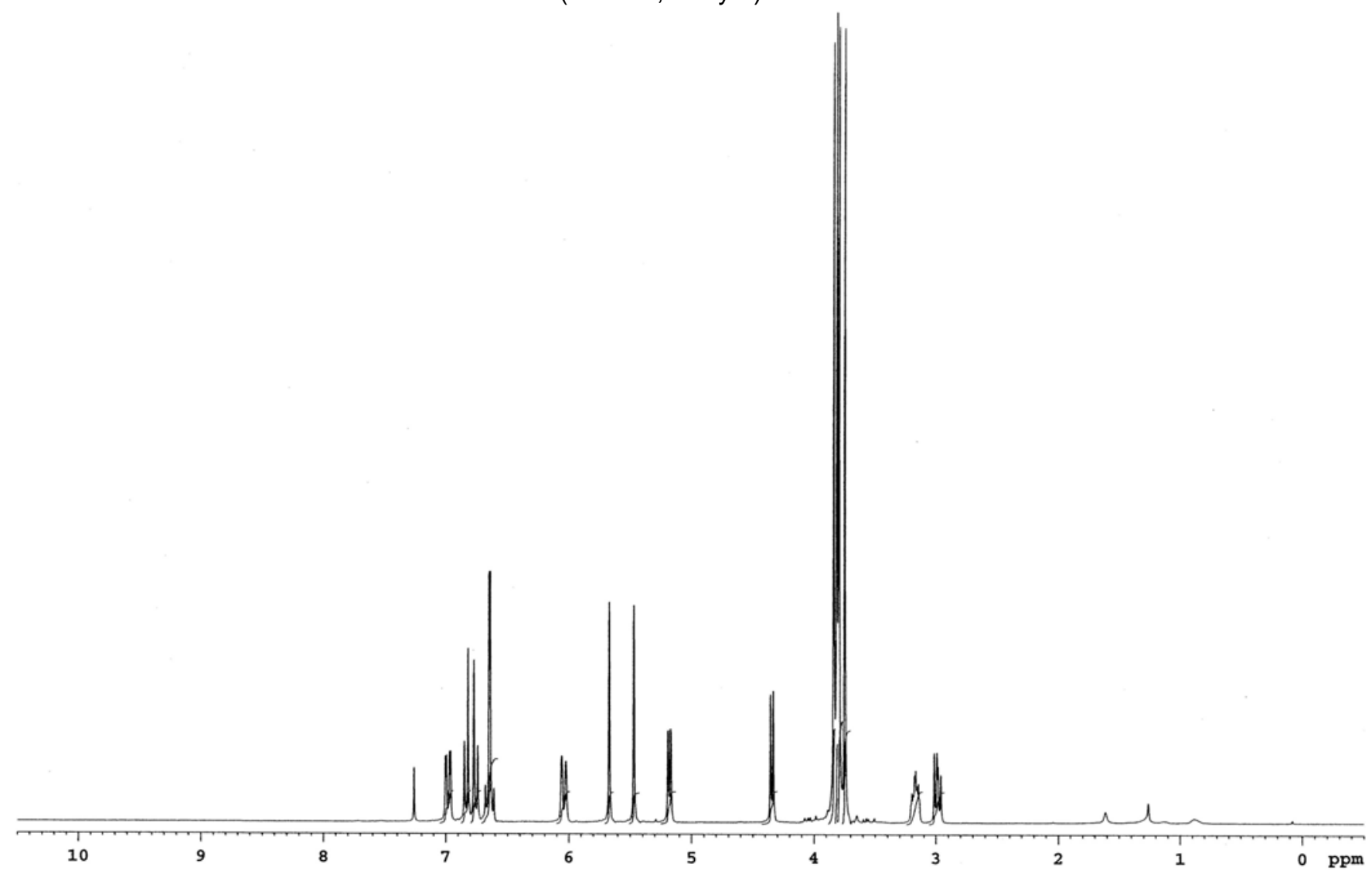
(300 $\mathrm{MHz}^{1} \mathrm{H}$ NMR spectrum, $\mathrm{CDCl}_{3}$ )

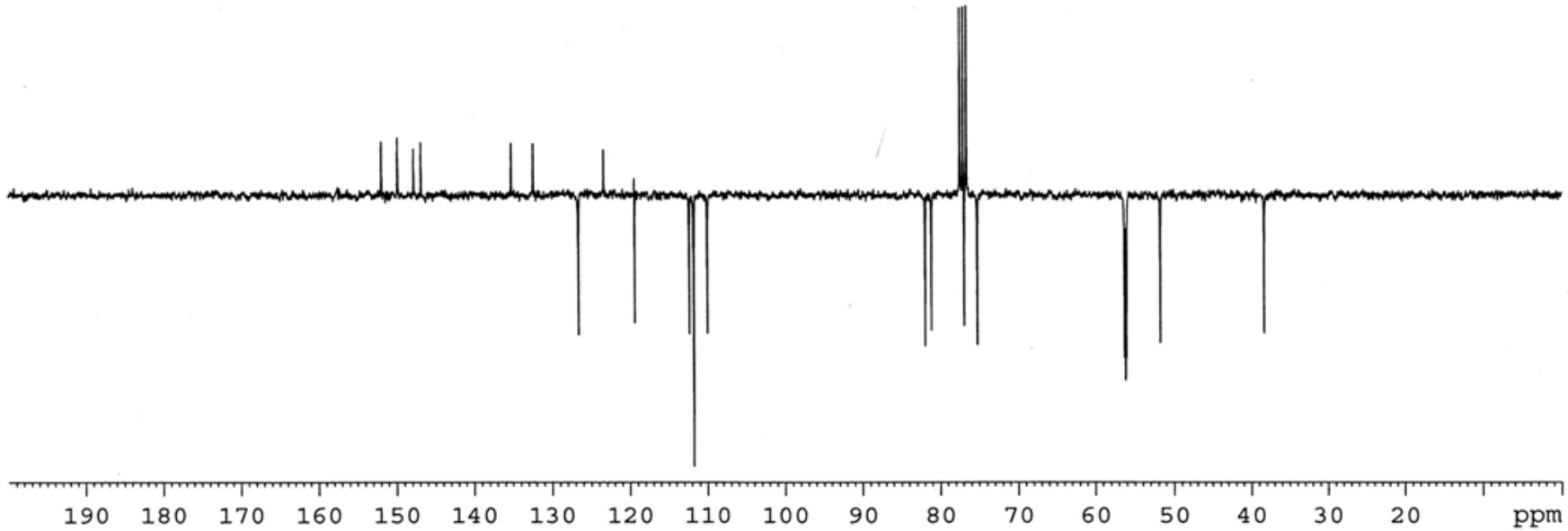



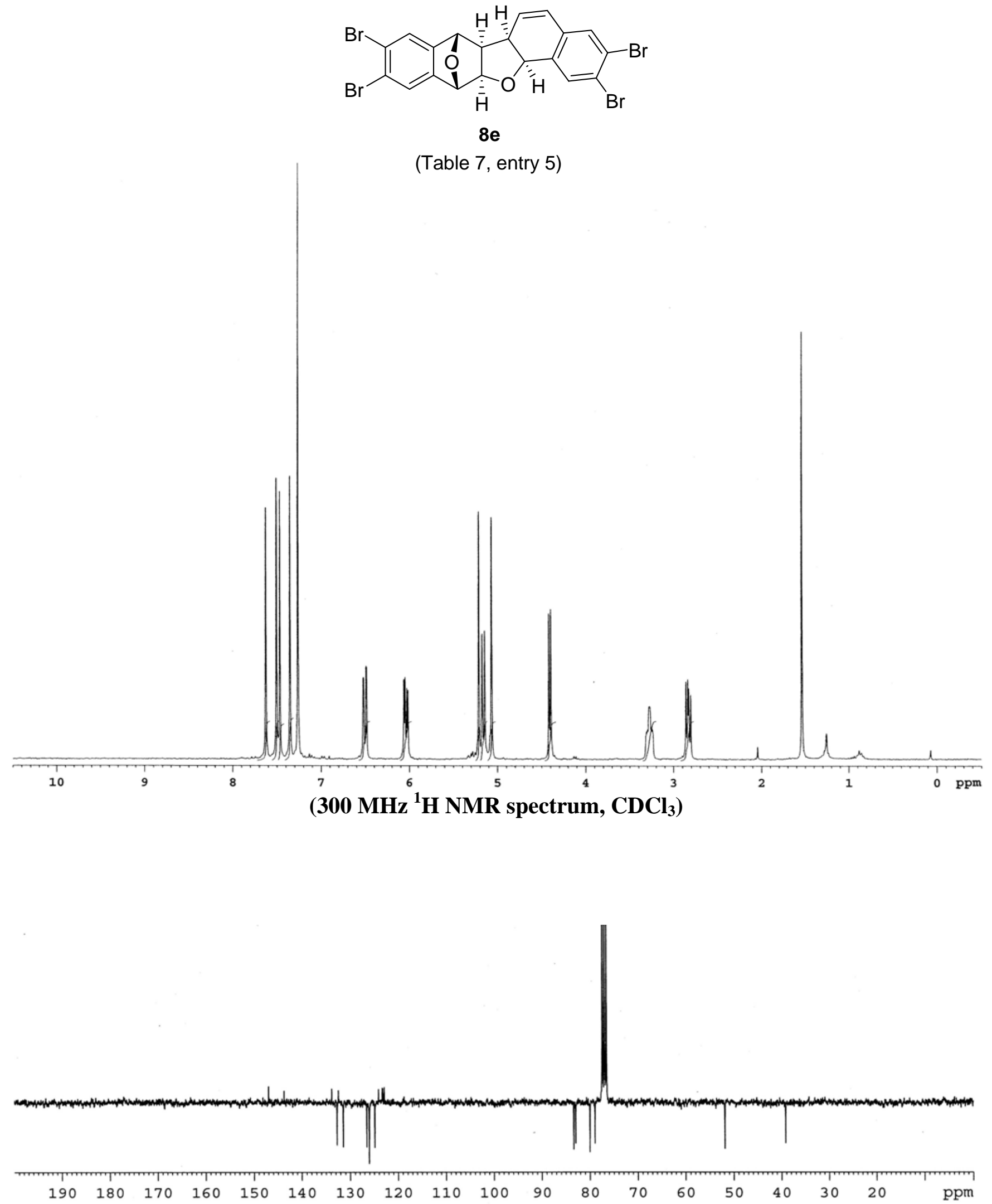

(75 $\mathrm{MHz}{ }^{13} \mathrm{C}$-APT NMR spectrum, $\mathrm{CDCl}_{3}$ ) 


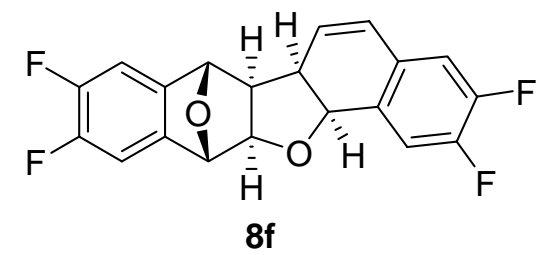

(Table 7, entry 6)
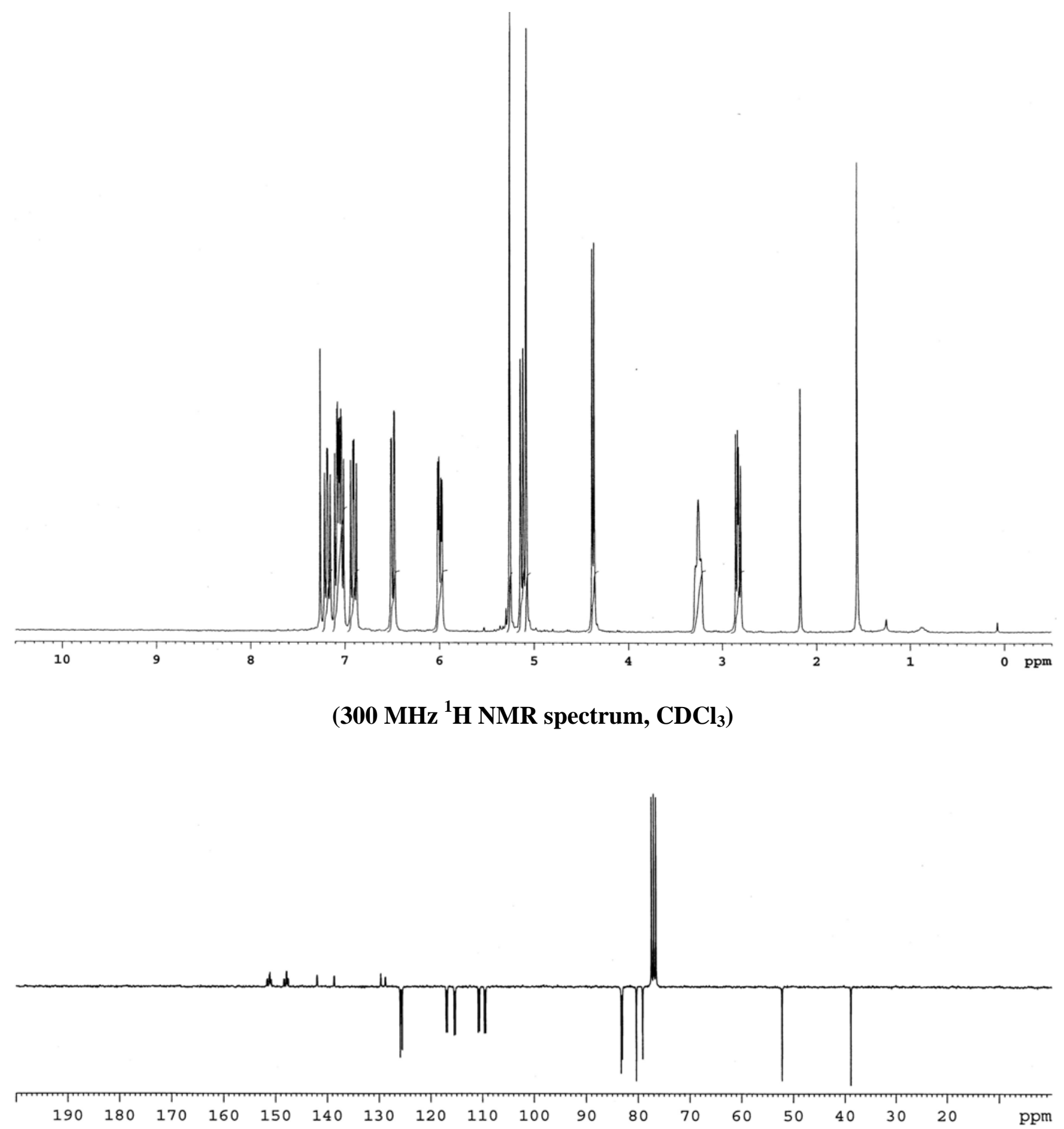

(75 $\mathrm{MHz}{ }^{13} \mathrm{C}$-APT NMR spectrum, $\mathrm{CDCl}_{3}$ ) 

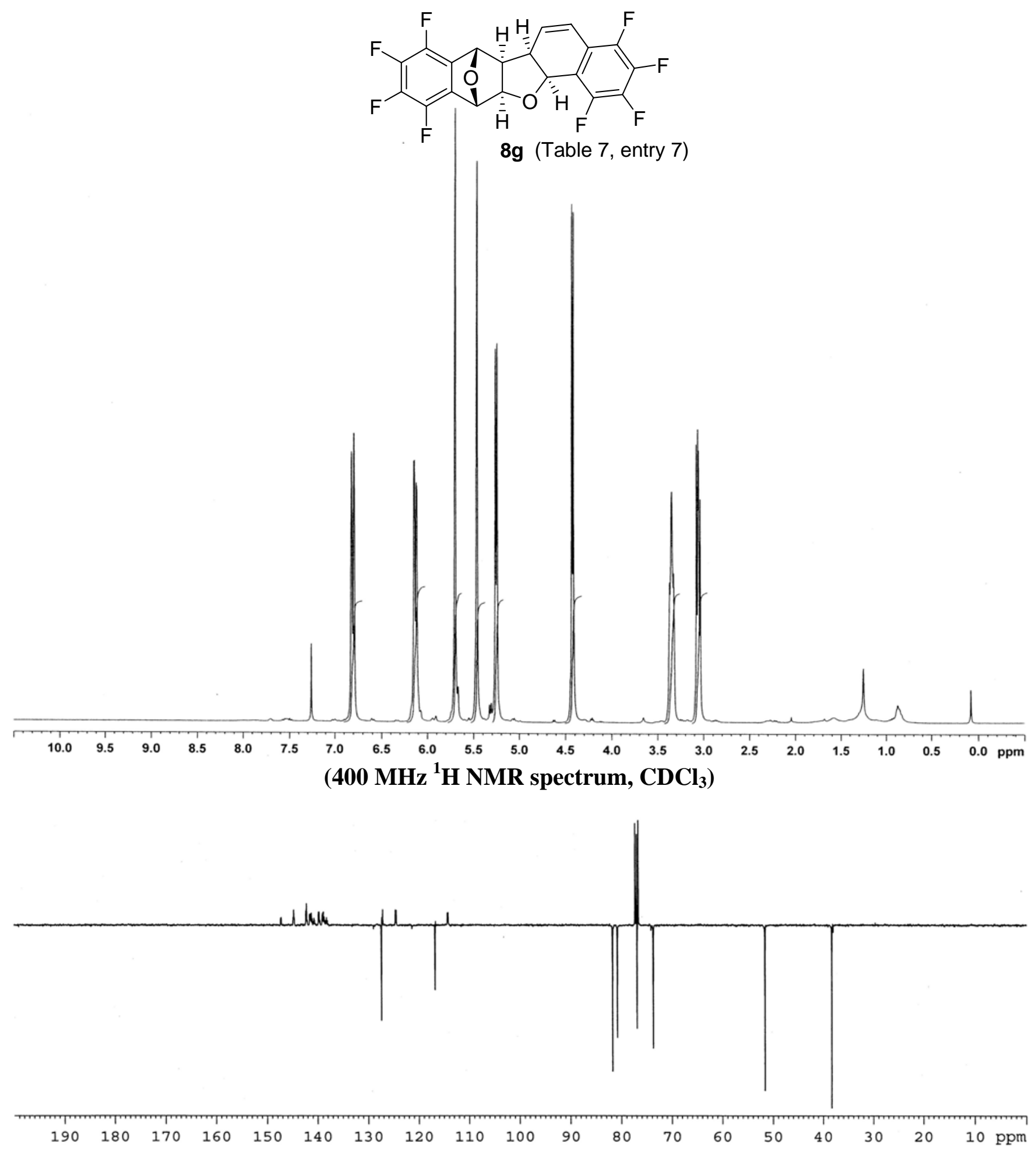

(100 MHz ${ }^{13} \mathrm{C}$-APT NMR spectrum, $\mathrm{CDCl}_{3}$ )

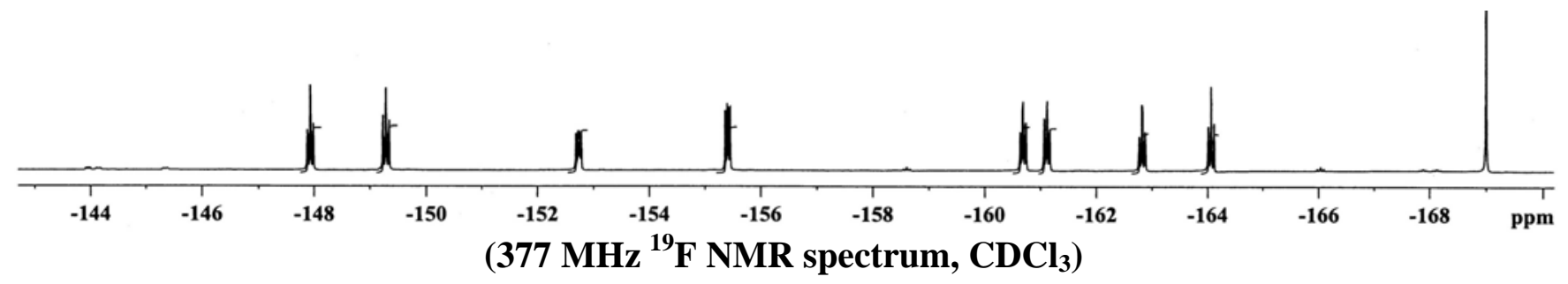




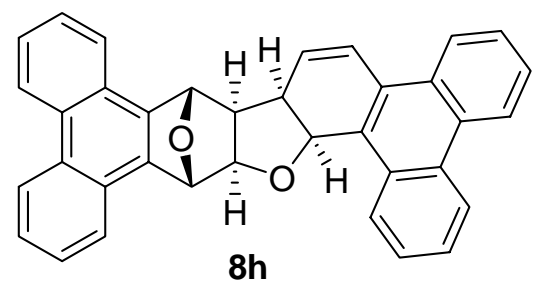

(Table 7, entry 8)

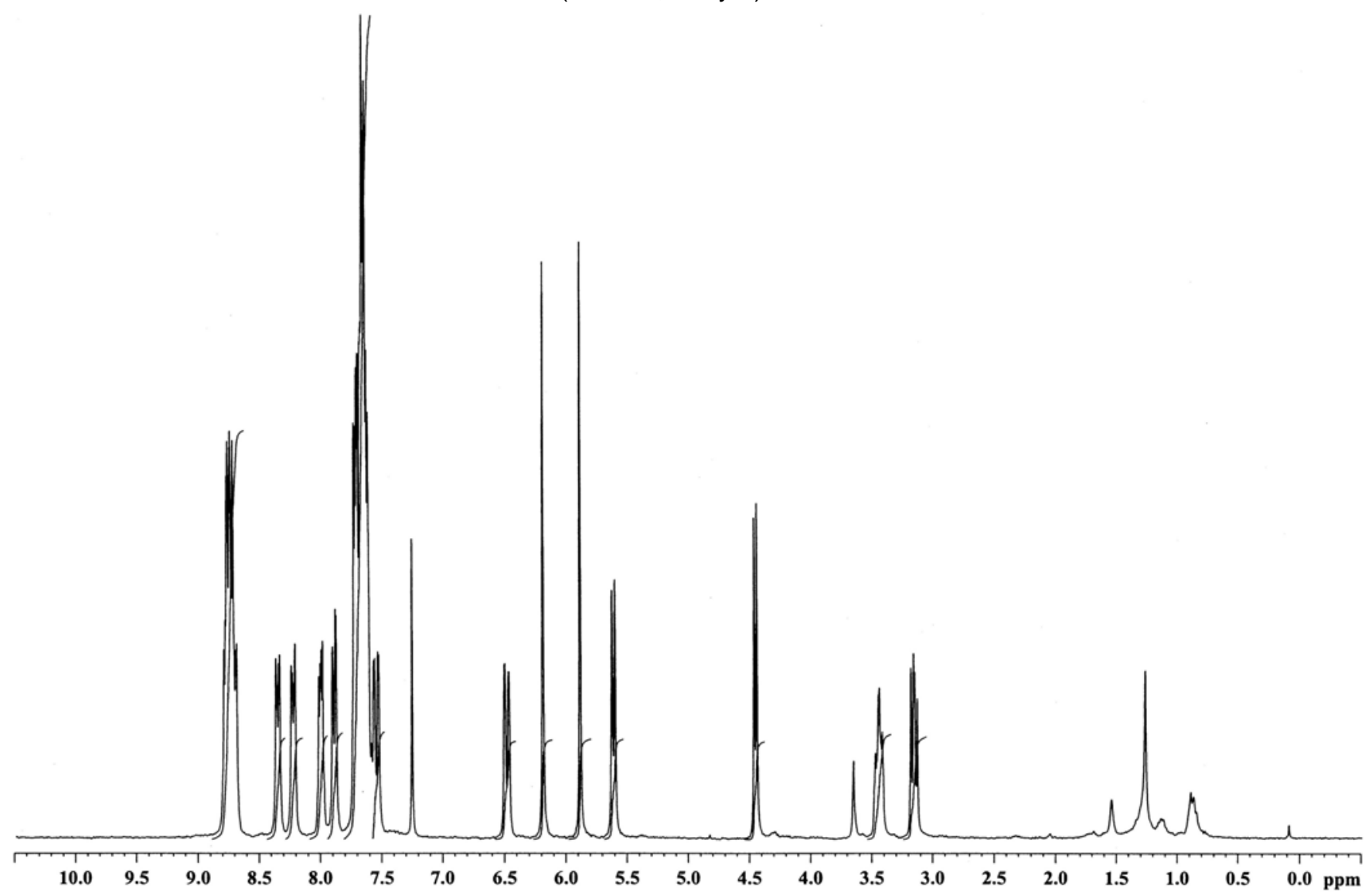

(300 $\mathrm{MHz}^{1} \mathrm{H}$ NMR spectrum, $\mathrm{CDCl}_{3}$ )

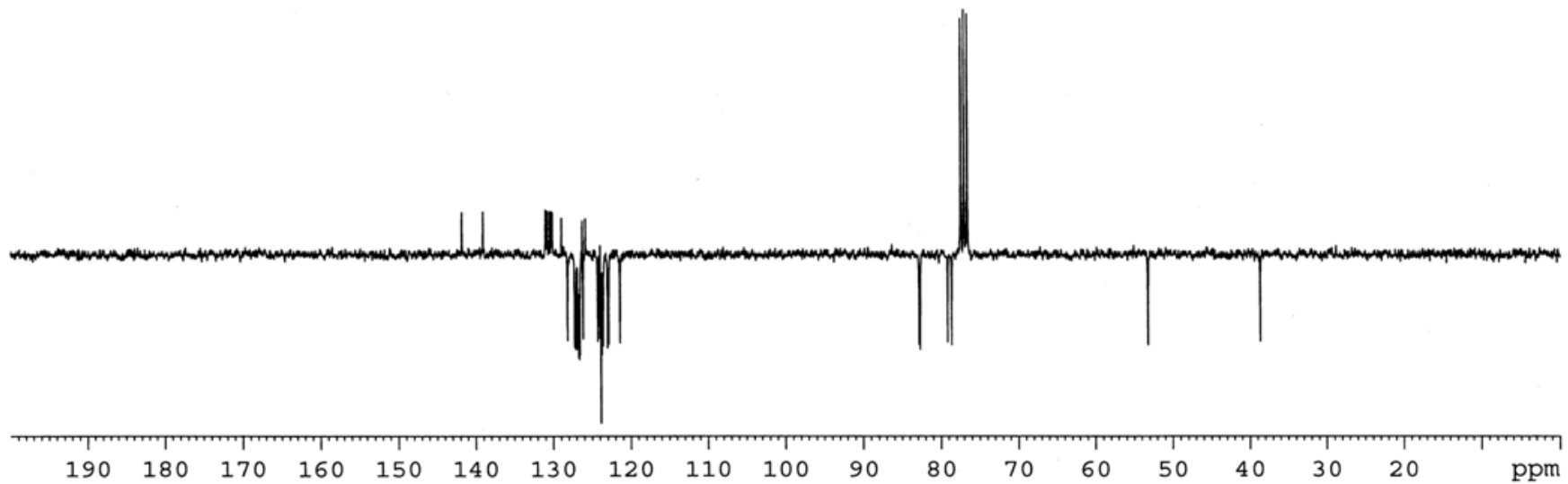

(75 $\mathrm{MHz}^{13} \mathrm{C}$-APT NMR spectrum, $\mathrm{CDCl}_{3}$ ) 


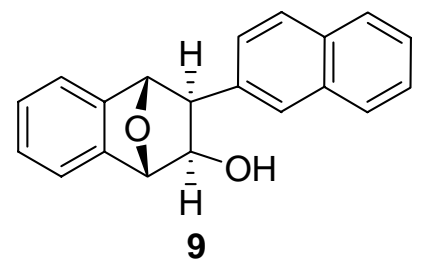

(Scheme 11)

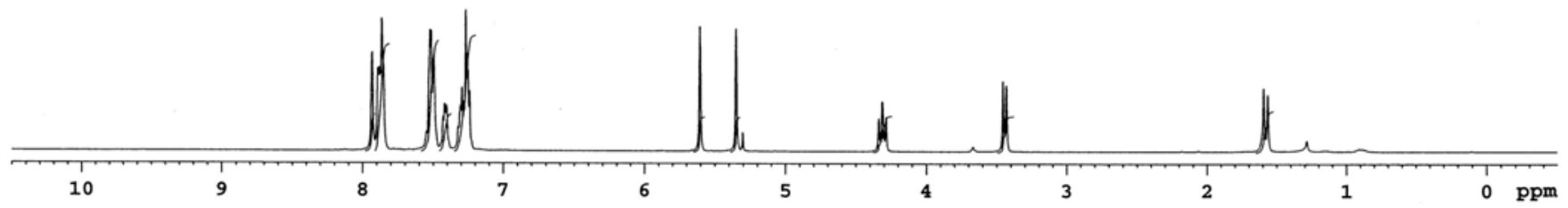
(300 $\mathrm{MHz}^{1} \mathrm{H}$ NMR spectrum, $\mathrm{CDCl}_{3}$ )

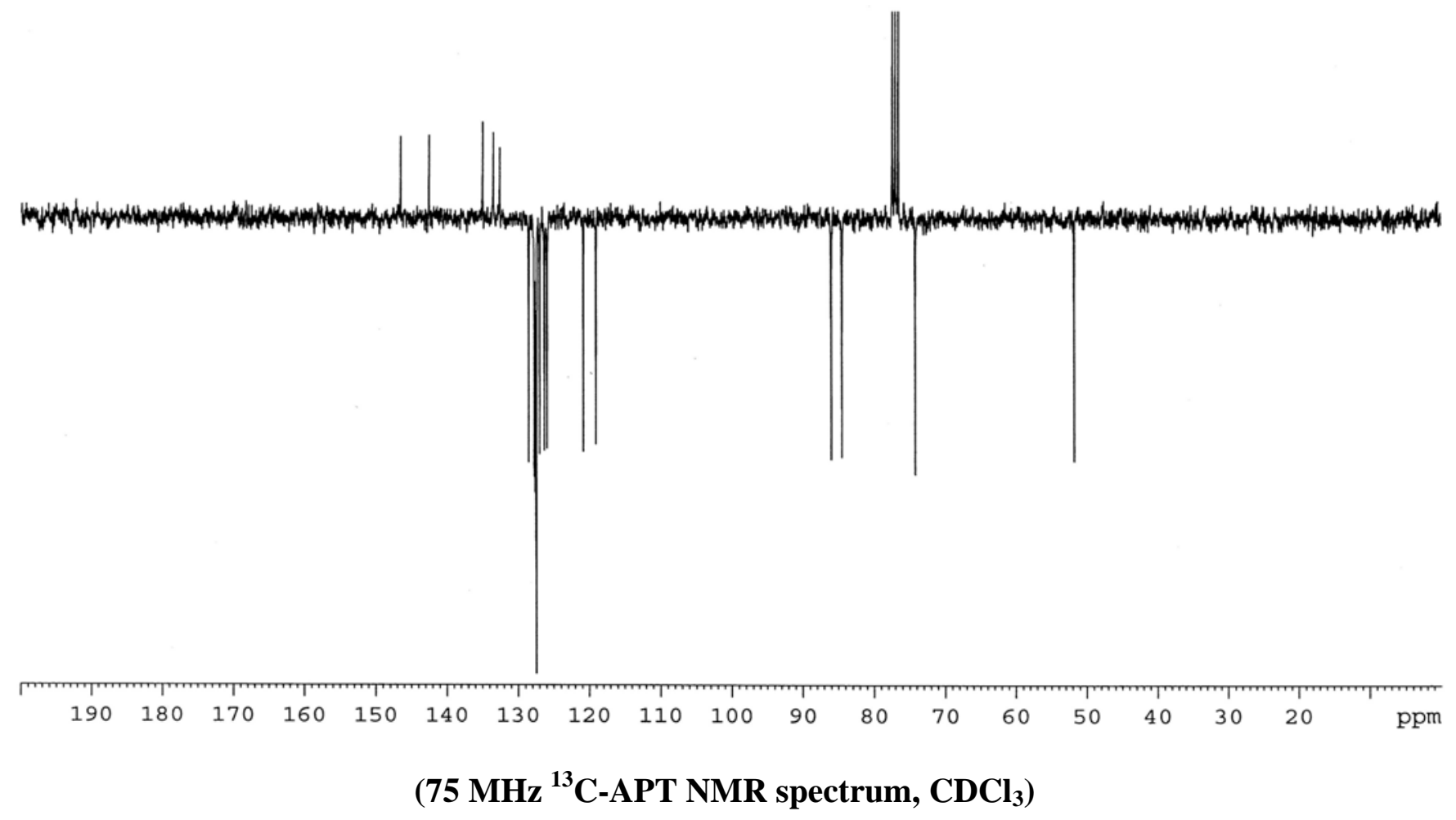




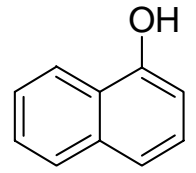

10

(Scheme 4)

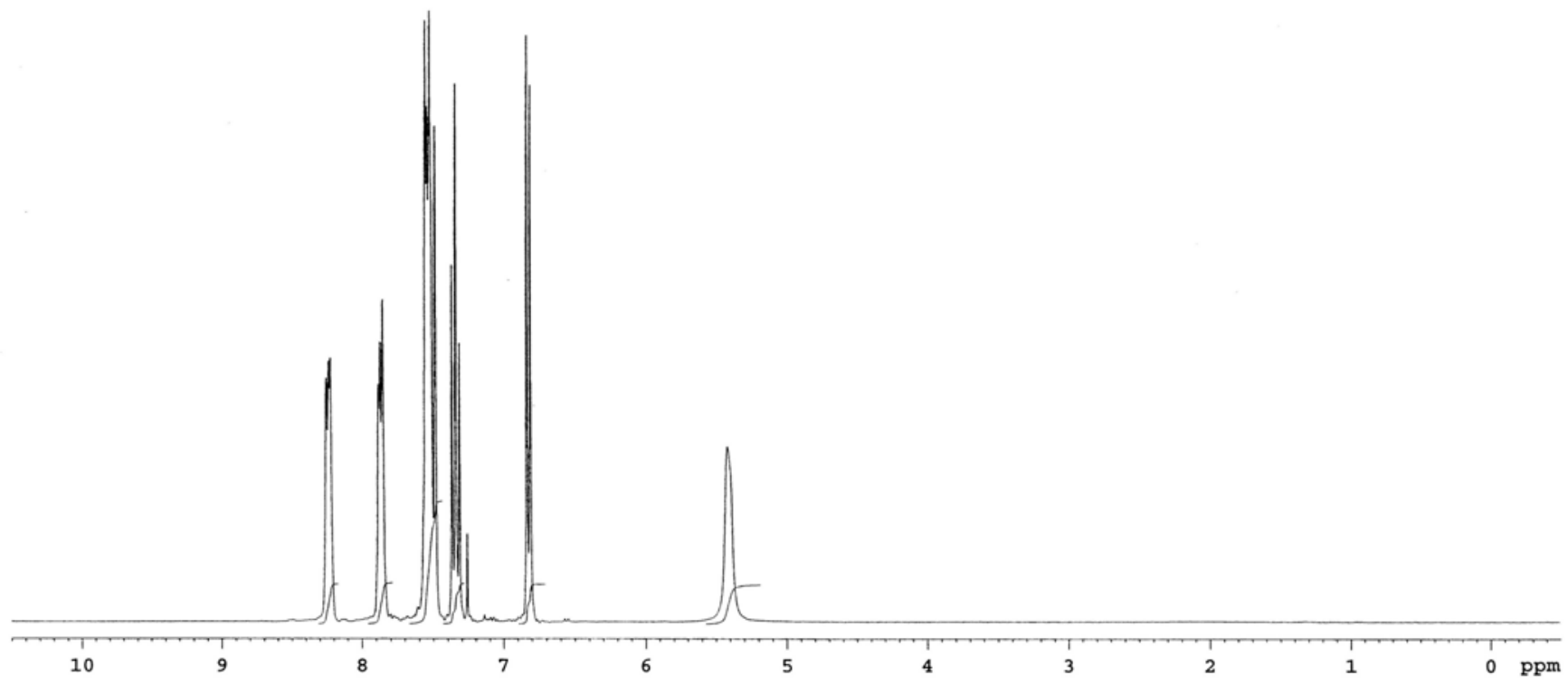

(300 $\mathrm{MHz}{ }^{1} \mathrm{H}$ NMR spectrum, $\mathrm{CDCl}_{3}$ )

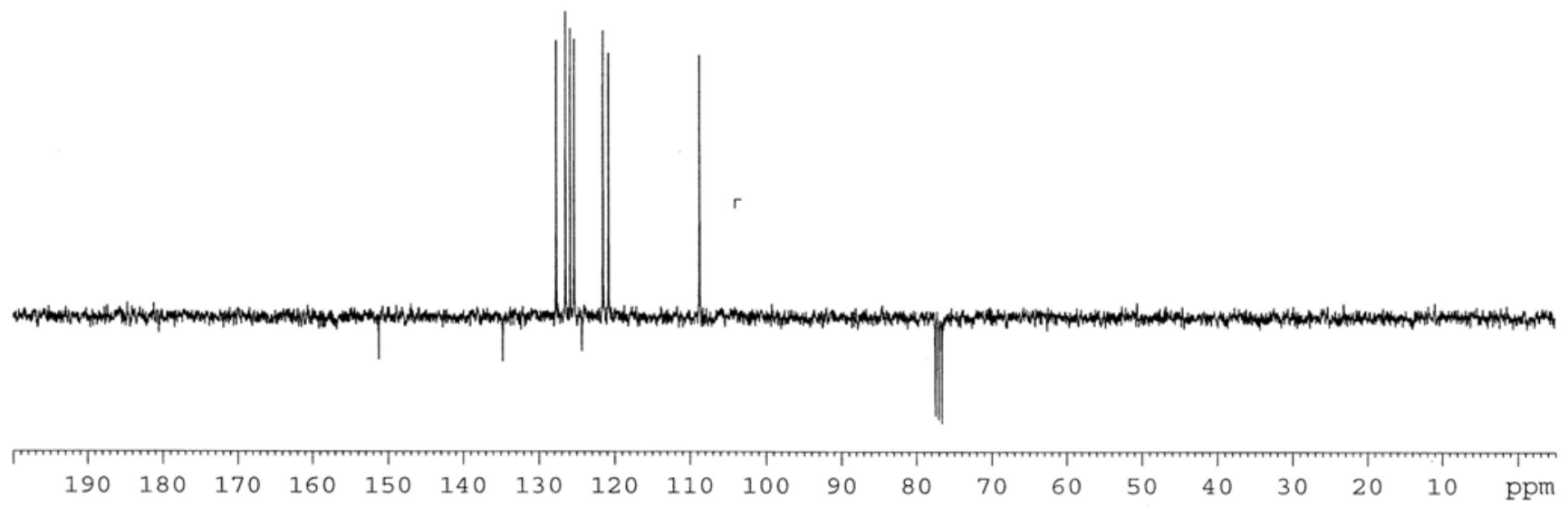

(75 $\mathrm{MHz}^{13} \mathrm{C}$-APT NMR spectrum, $\mathrm{CDCl}_{3}$ ) 


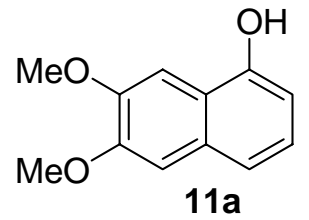

(Scheme 5)

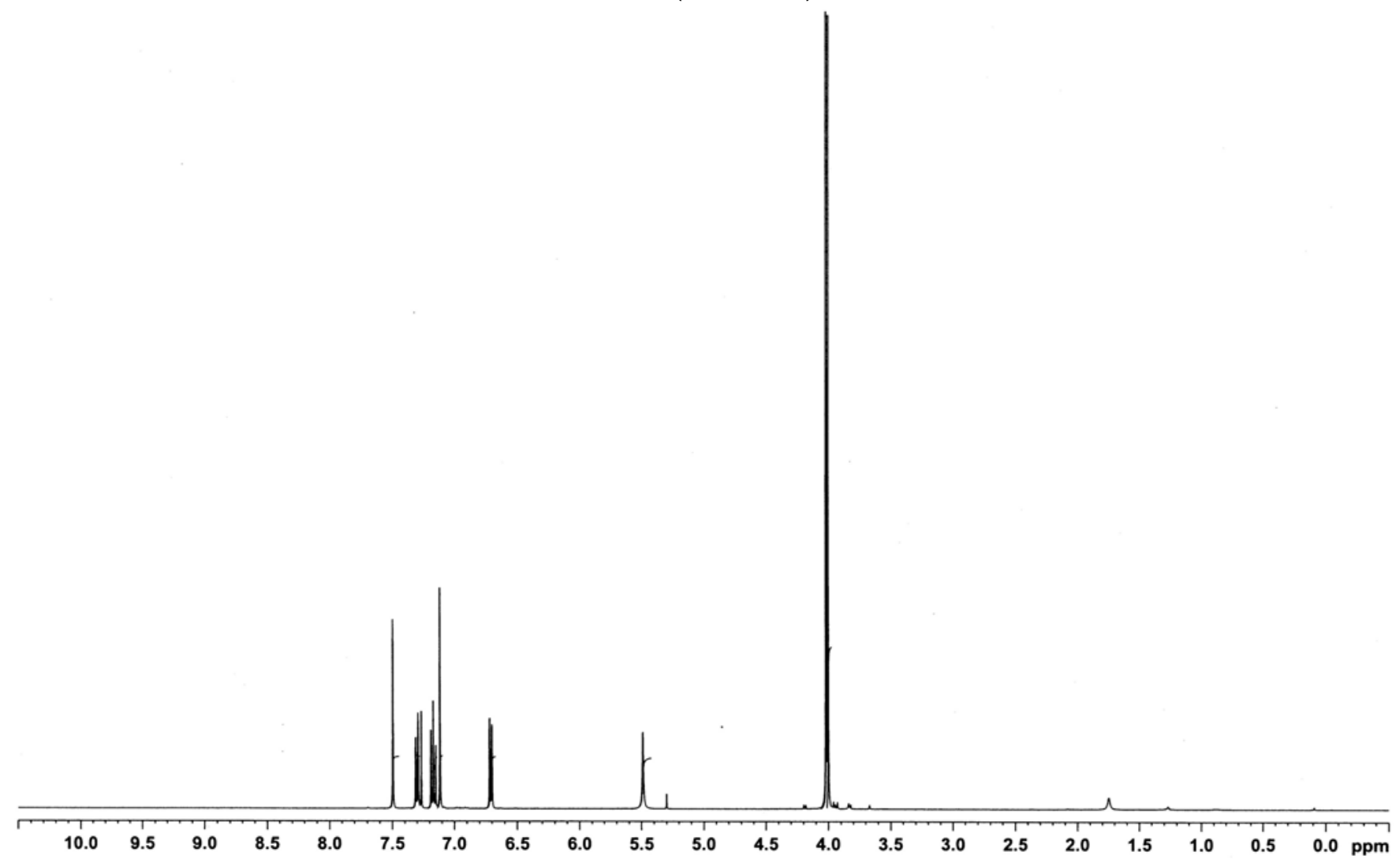

(400 $\mathrm{MHz}^{1} \mathrm{H}$ NMR spectrum, $\mathrm{CDCl}_{3}$ )

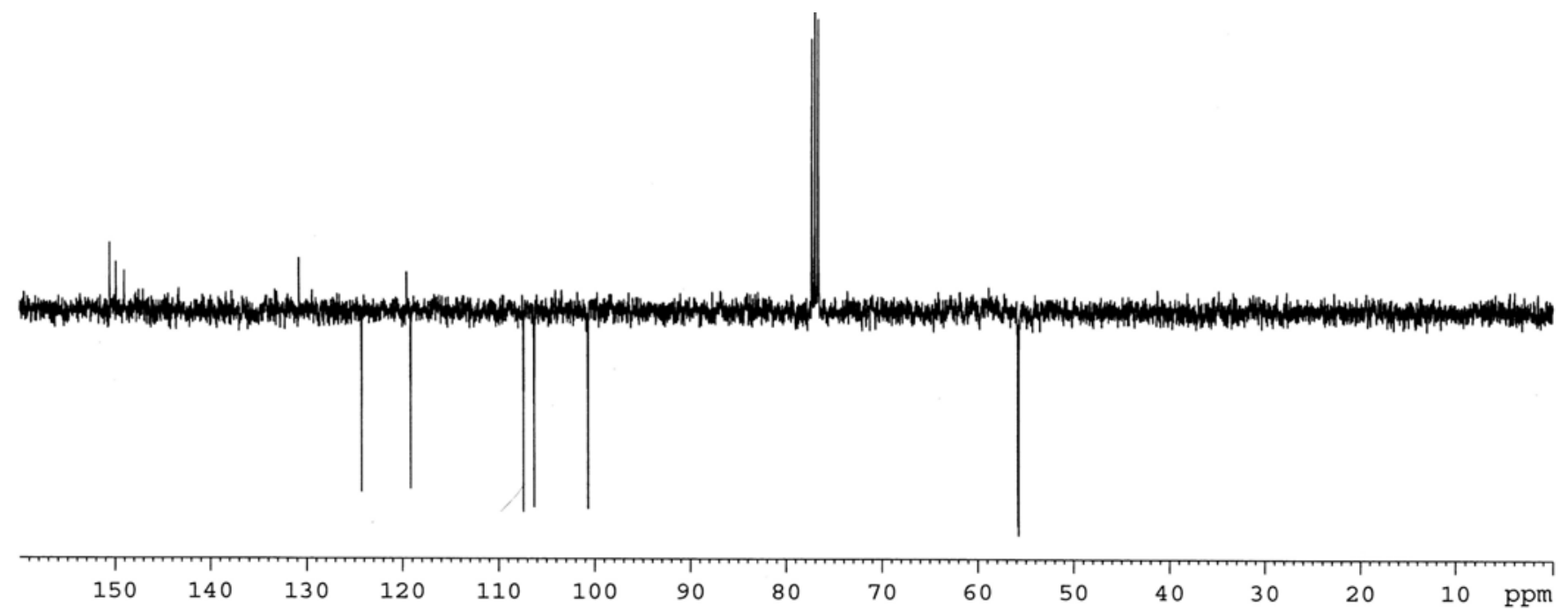

(100 $\mathrm{MHz}^{13} \mathrm{C}$-APT NMR spectrum, $\mathrm{CDCl}_{3}$ ) 


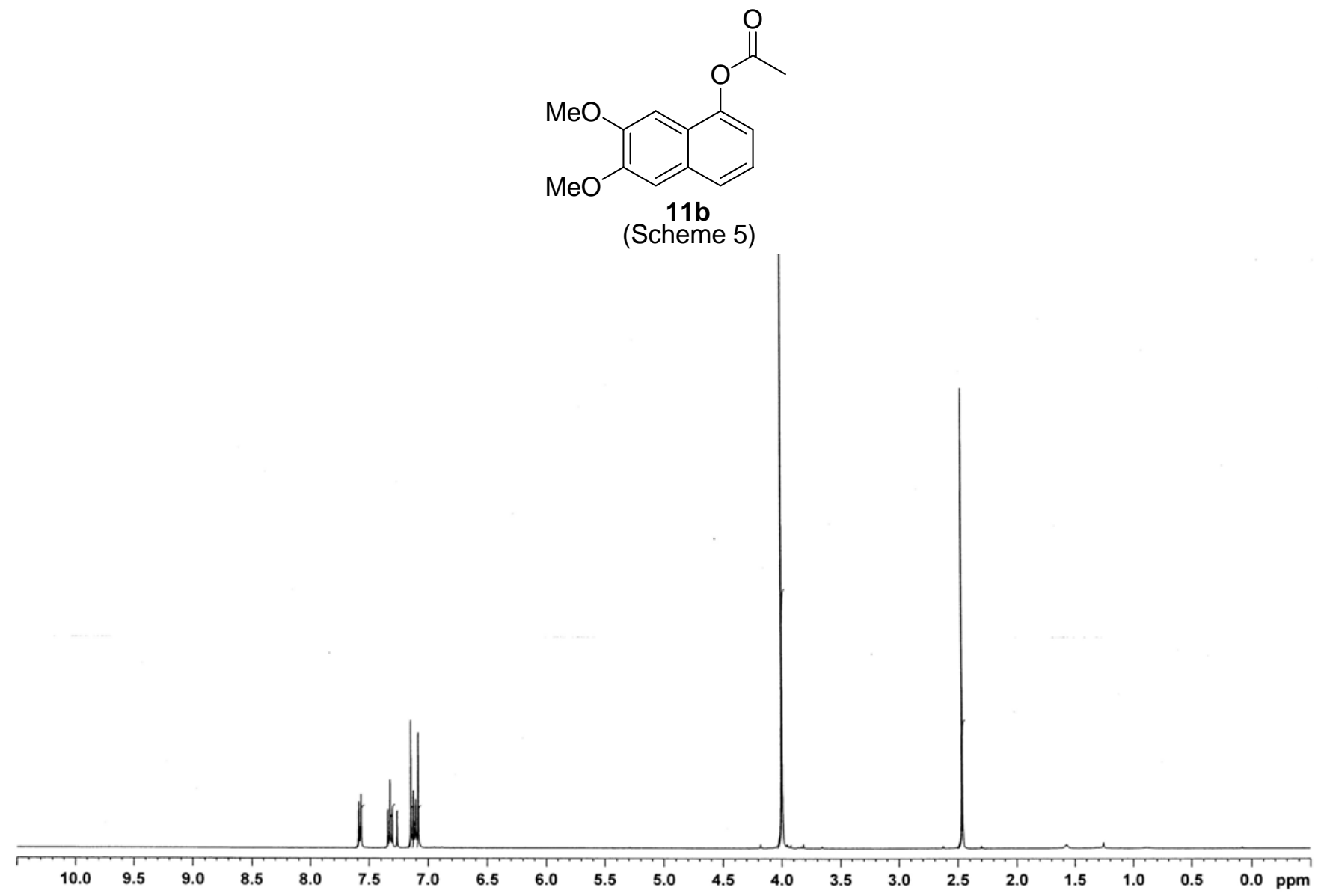

(400 $\mathrm{MHz}^{1} \mathrm{H}$ NMR spectrum, $\mathrm{CDCl}_{3}$ )

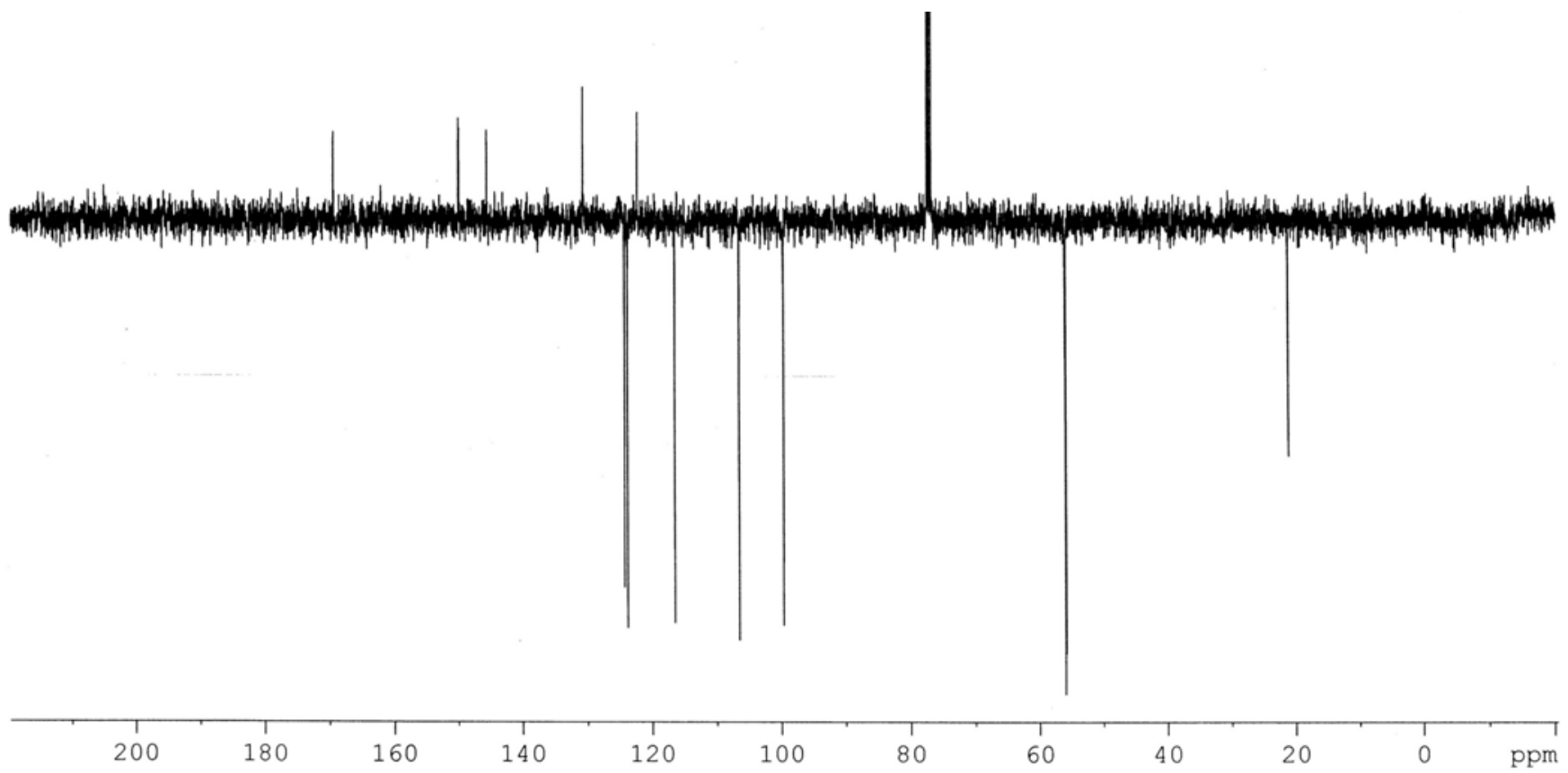

(100 $\mathrm{MHz}{ }^{13} \mathrm{C}$-APT NMR spectrum, $\mathrm{CDCl}_{3}$ ) 

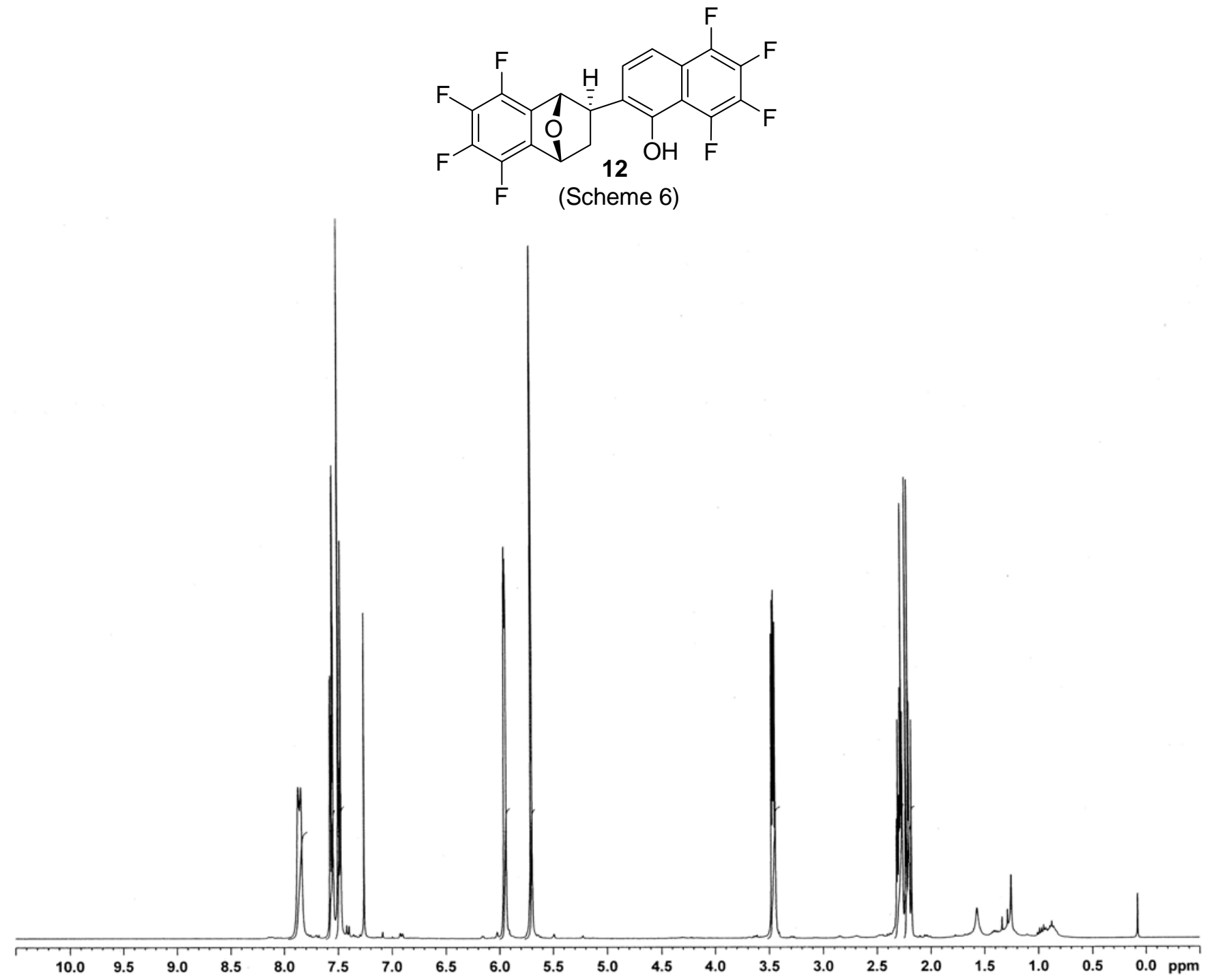

(400 $\mathrm{MHz}^{1} \mathrm{H}$ NMR spectrum, $\mathrm{CDCl}_{3}$ )

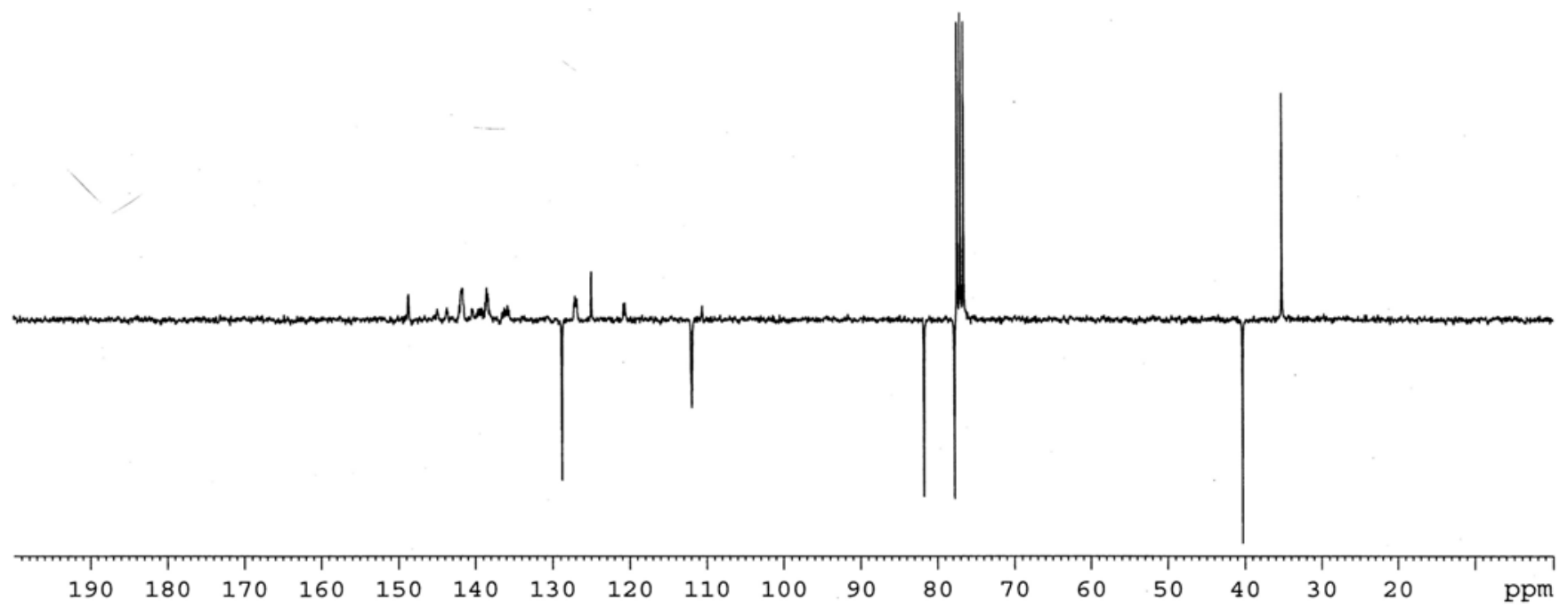

(75 $\mathrm{MHz}{ }^{13} \mathrm{C}$-APT NMR spectrum, $\mathrm{CDCl}_{3}$ ) 


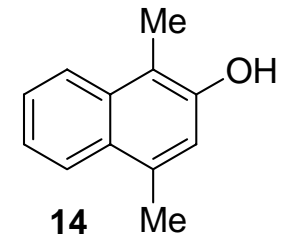

(Scheme 7)

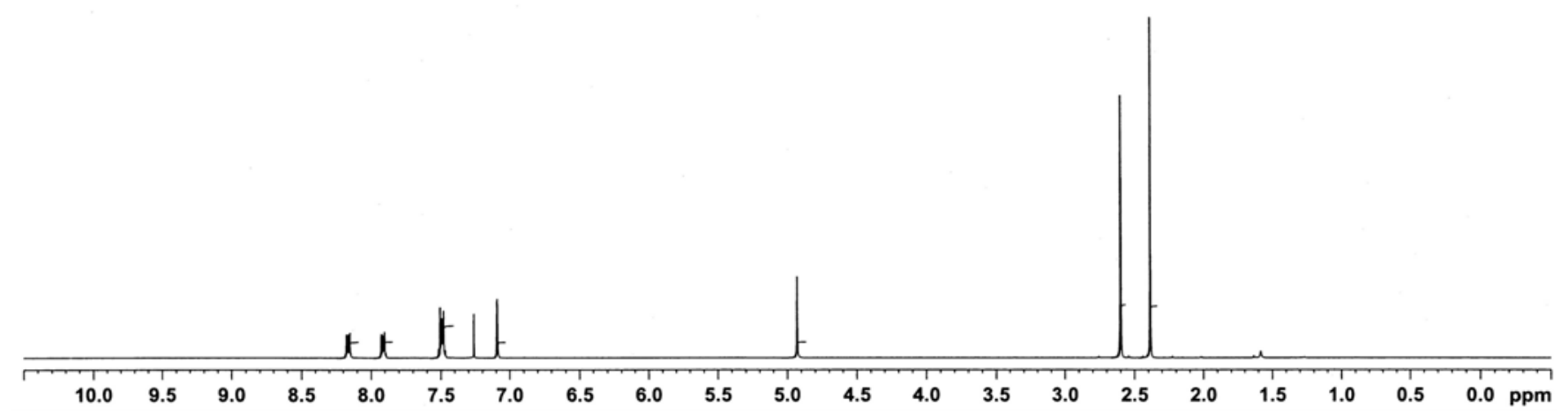

(400 $\mathrm{MHz}^{1} \mathrm{H}$ NMR spectrum, $\mathrm{CDCl}_{3}$ )

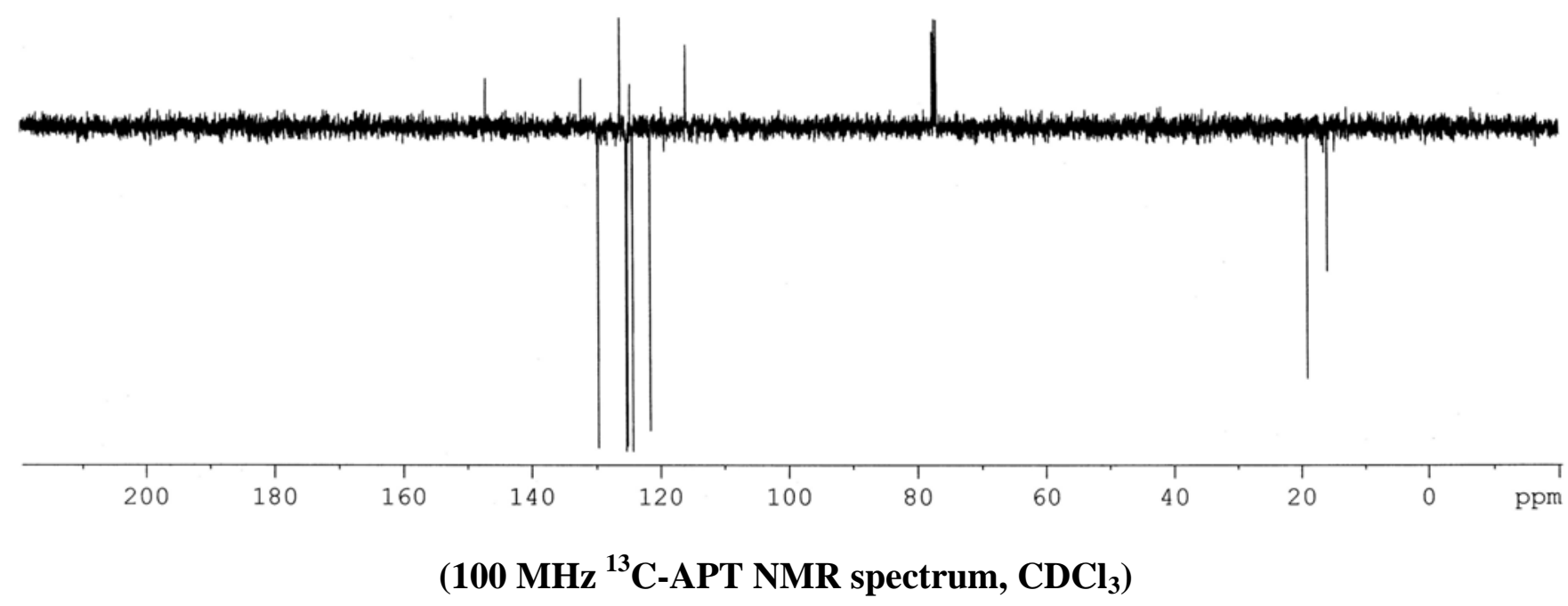




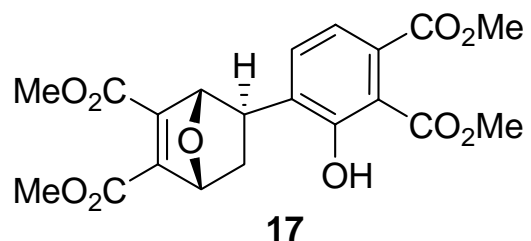

(Scheme 8)

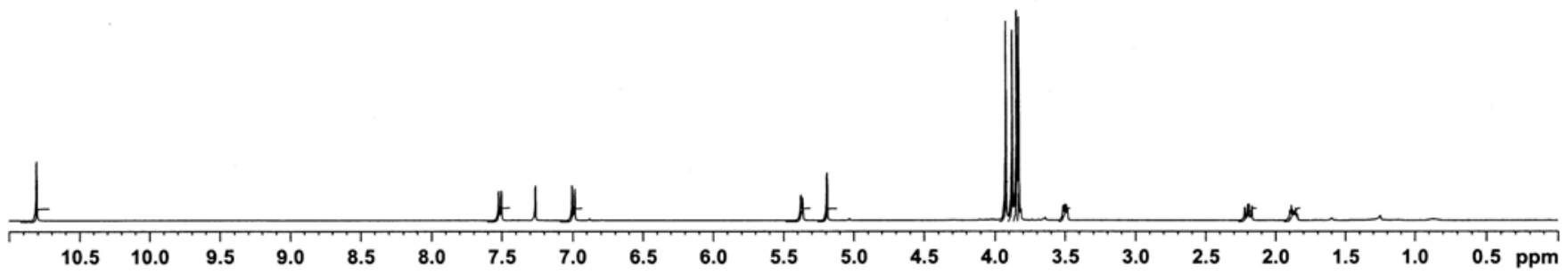

(400 $\mathrm{MHz}{ }^{1} \mathrm{H}$ NMR spectrum, $\mathrm{CDCl}_{3}$ )

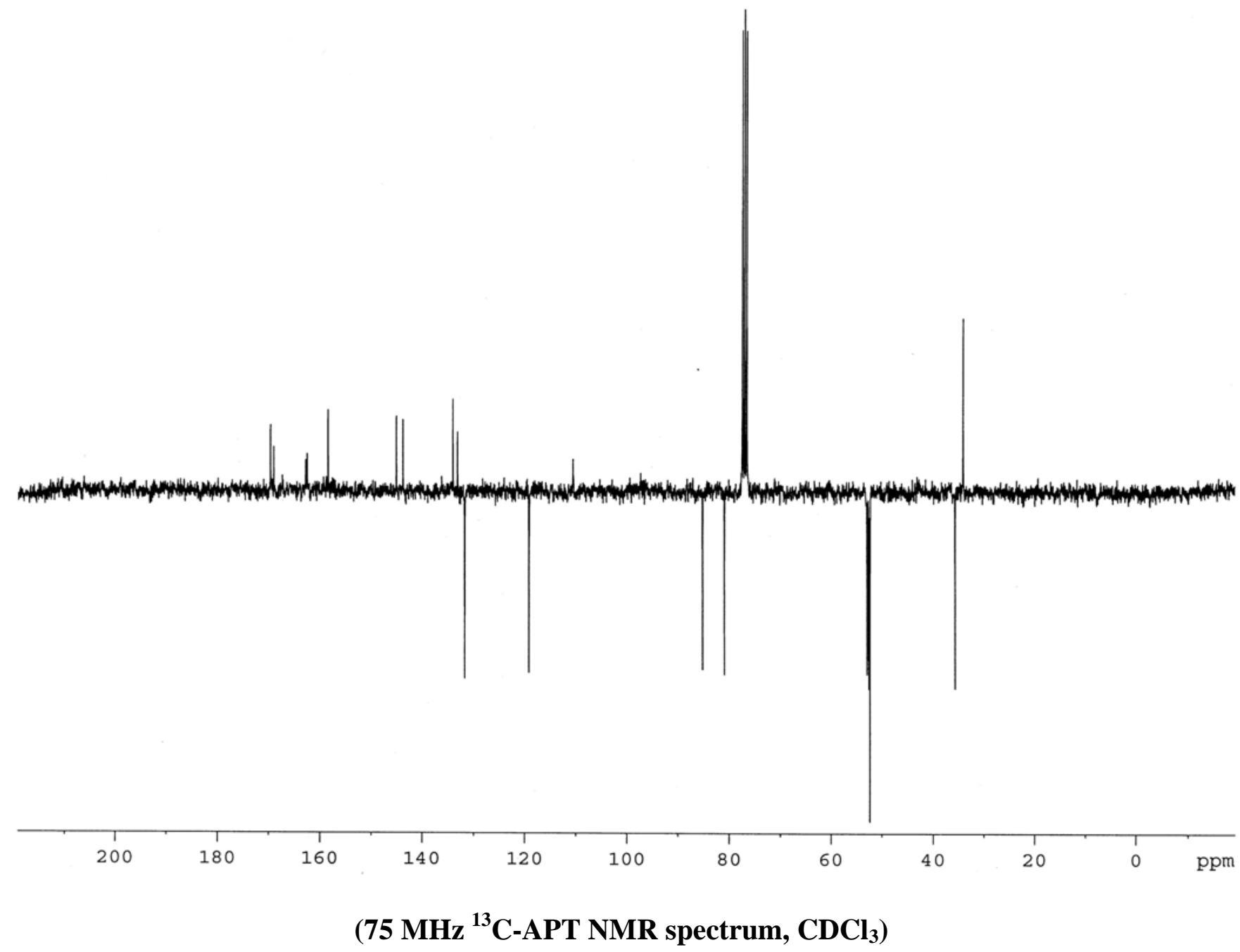




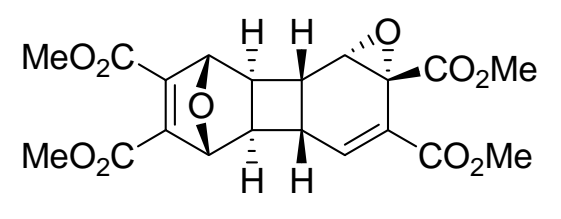

18

(Scheme 8)

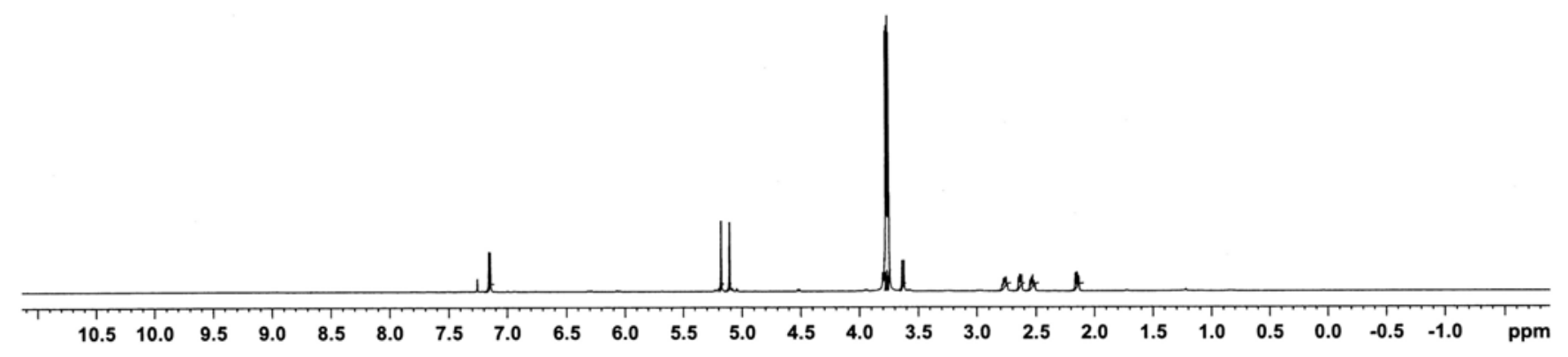

(400 MHz ${ }^{1} \mathrm{H}$ NMR spectrum, $\mathrm{CDCl}_{3}$ )

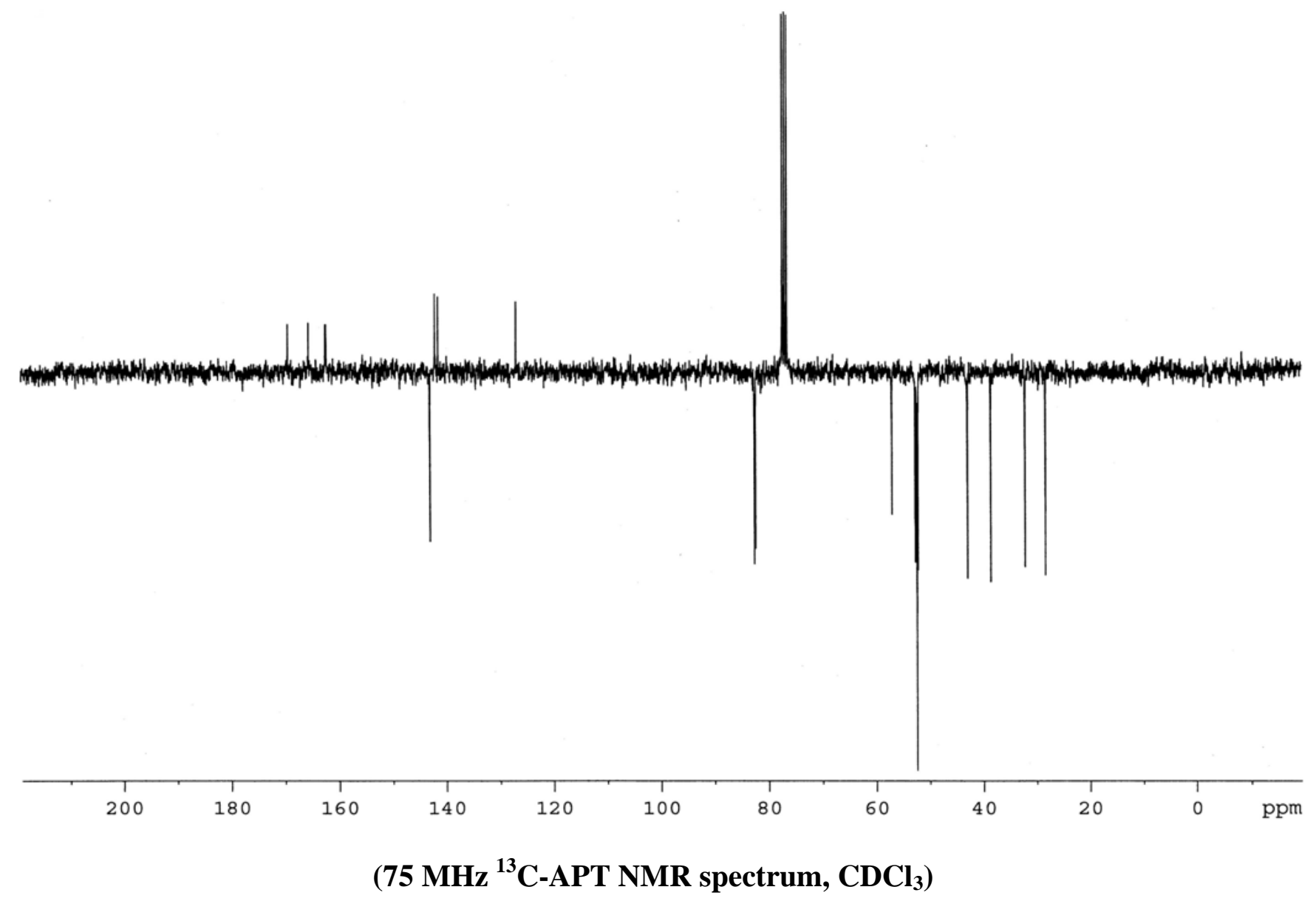




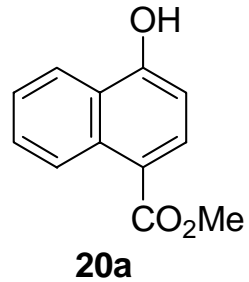

(Table 8 , entry 1 )

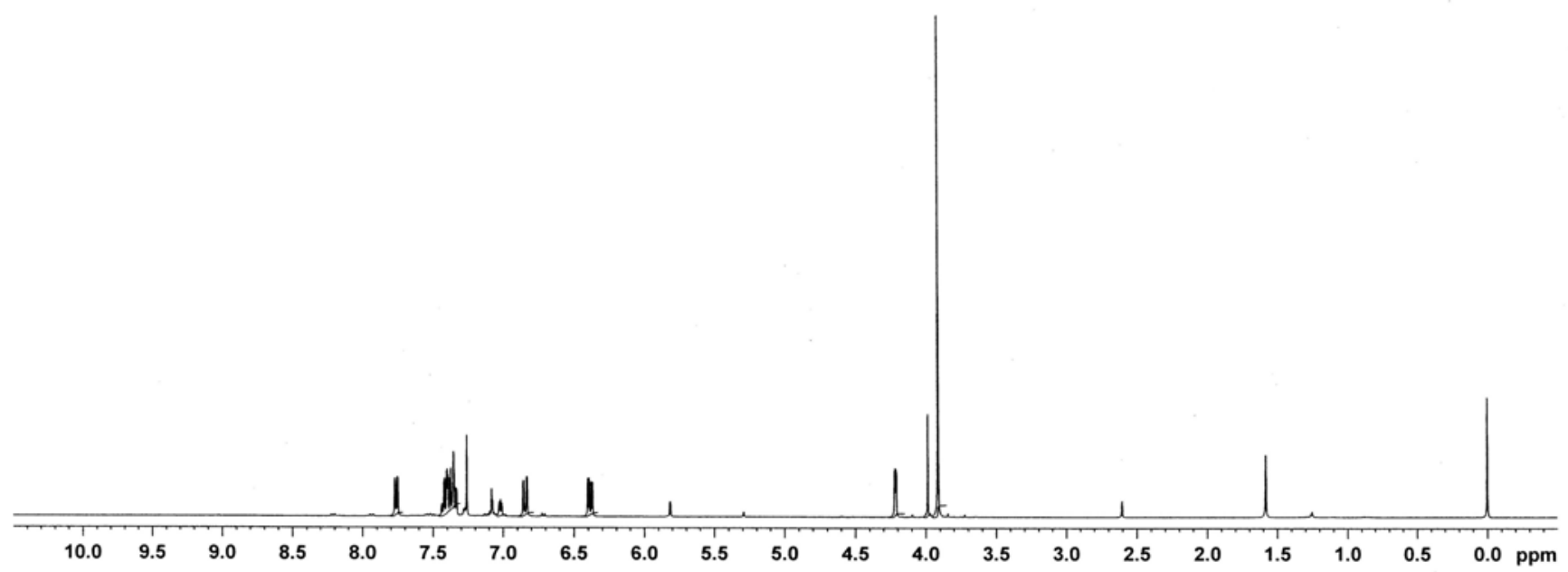
(400 $\mathrm{MHz}{ }^{1} \mathrm{H}$ NMR spectrum, $\mathrm{CDCl}_{3}$ )

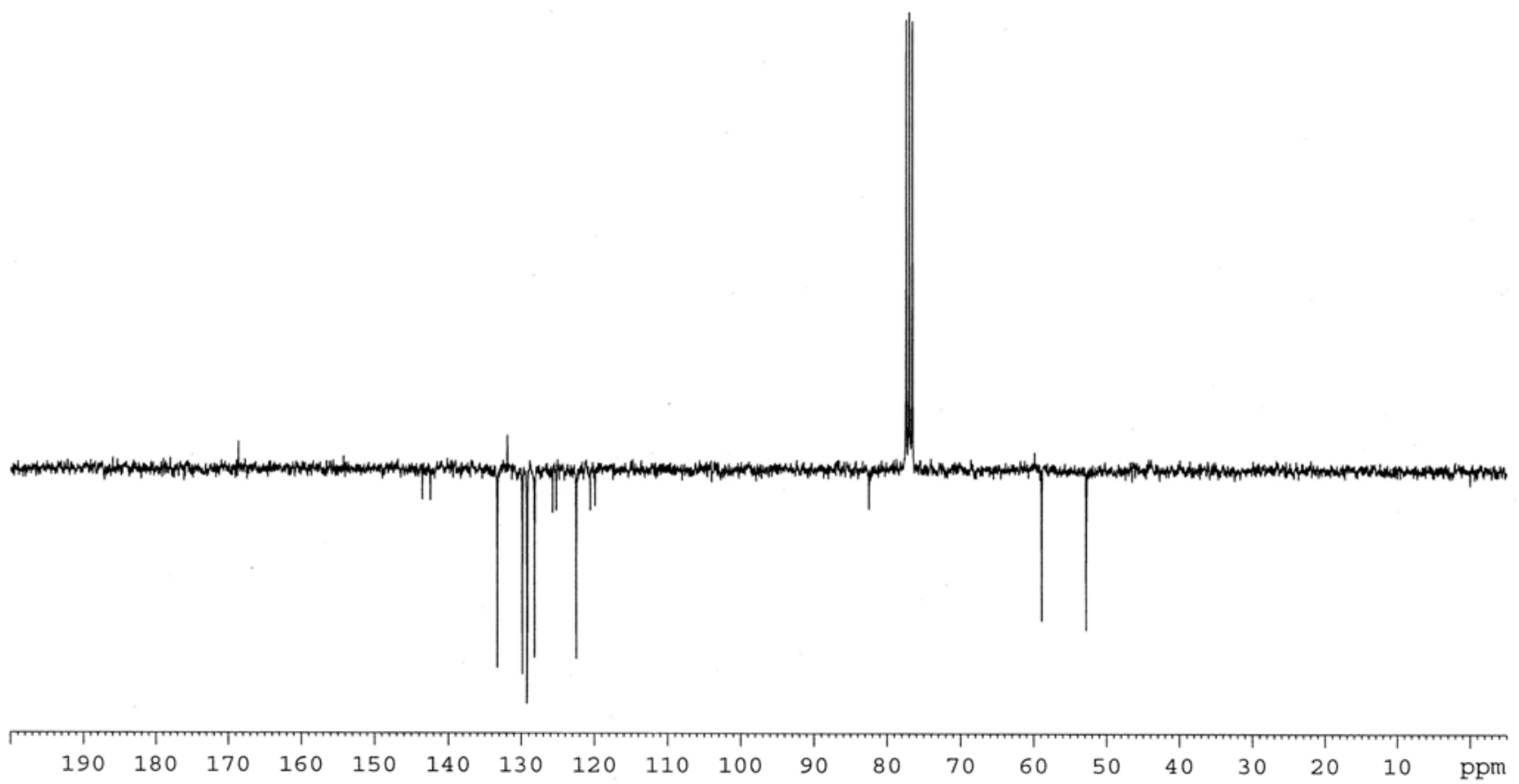

(75 $\mathrm{MHz}^{13} \mathrm{C}$-APT NMR spectrum, $\mathrm{CDCl}_{3}$ ) 


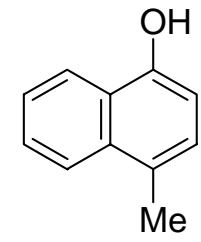

20b

(Table 8 , entry 2 )

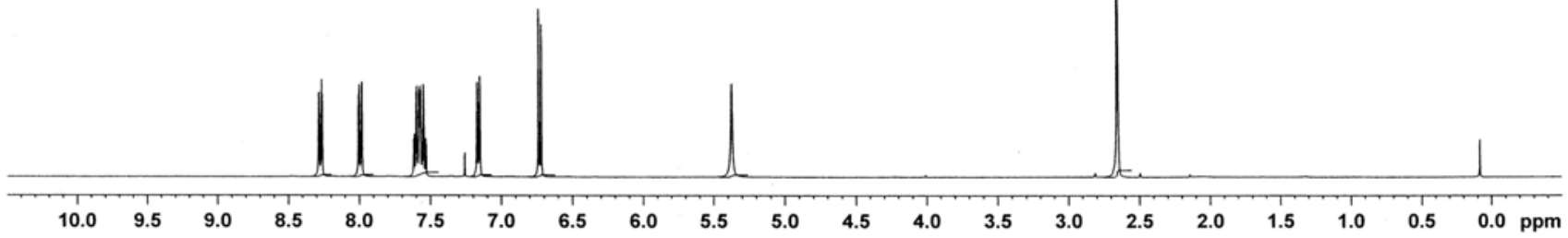

\section{(400 $\mathrm{MHz}^{1} \mathrm{H}$ NMR spectrum, $\mathrm{CDCl}_{3}$ )}

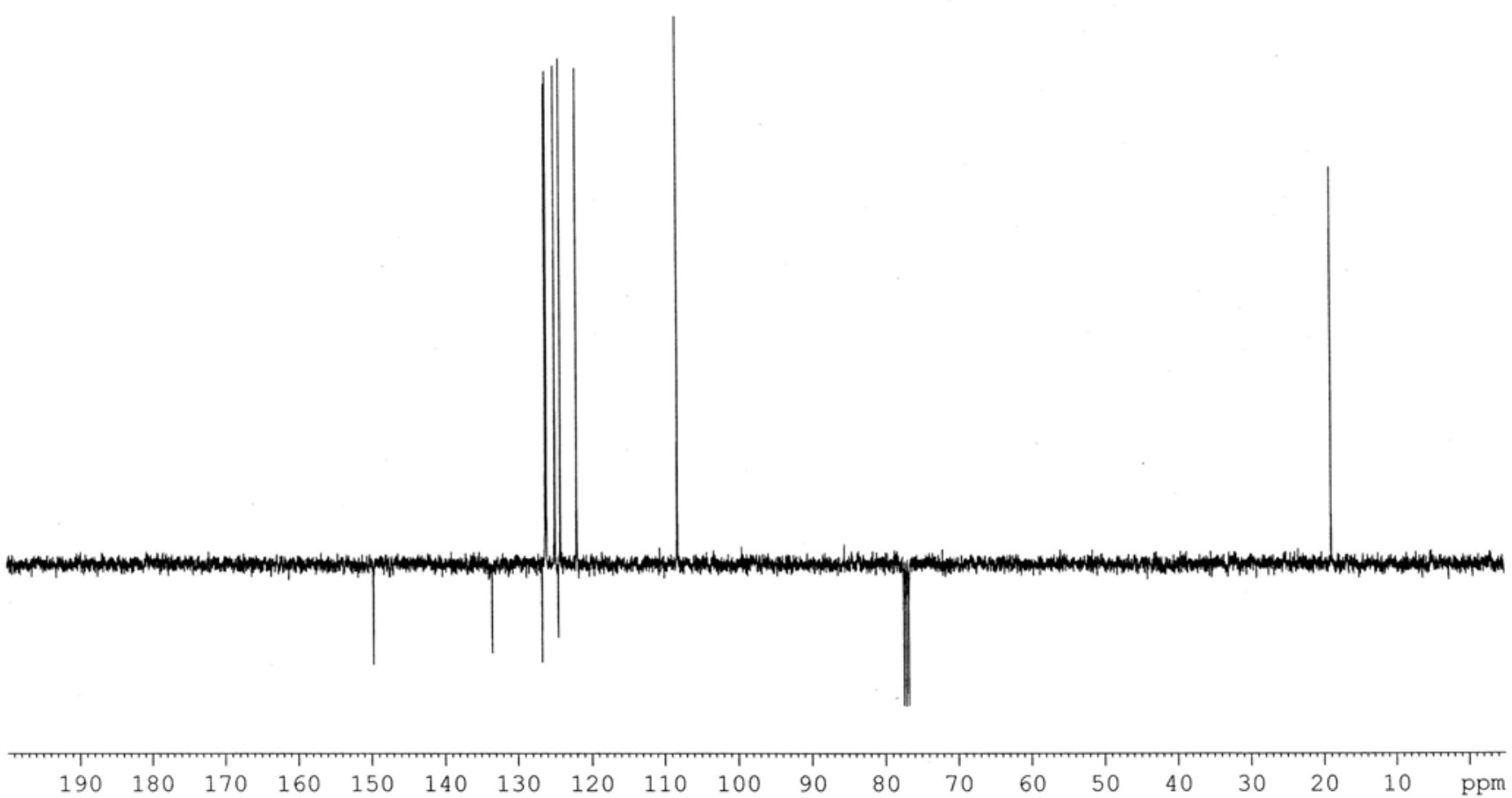

$\left(100 \mathrm{MHz}^{13} \mathrm{C}\right.$-APT NMR spectrum, $\mathrm{CDCl}_{3}$ ) 


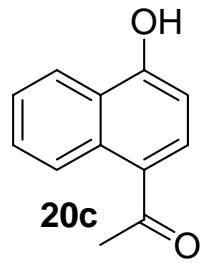

(Table 8, entry 3)

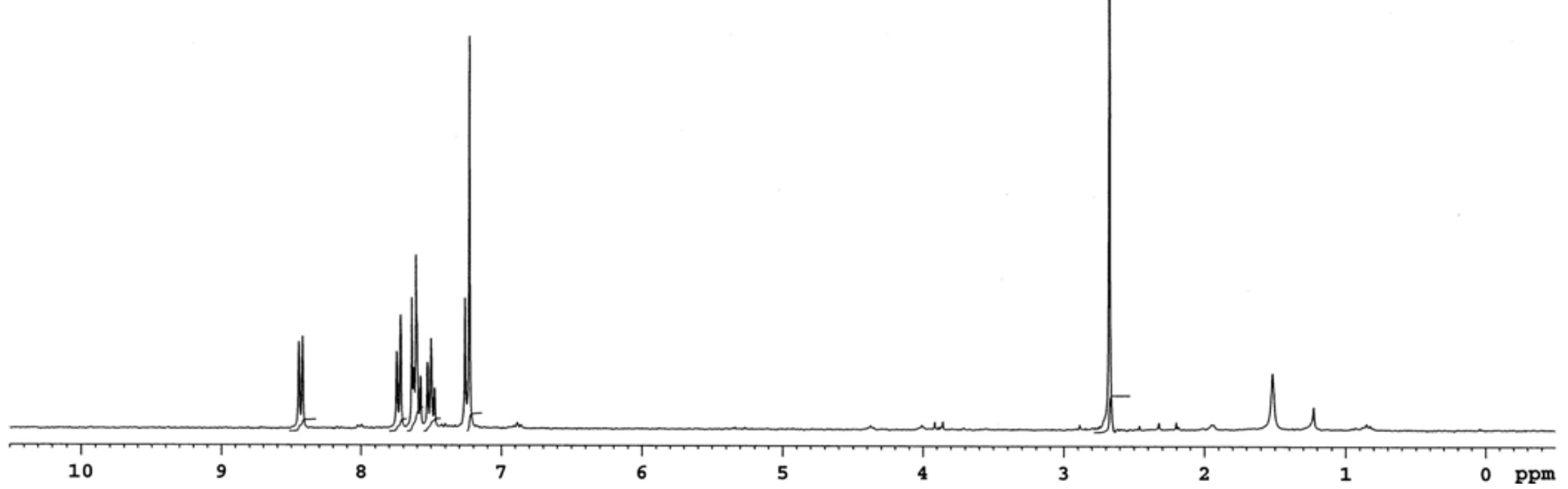

(300 $\mathrm{MHz}{ }^{1} \mathrm{H}$ NMR spectrum, $\mathrm{CDCl}_{3}$ )

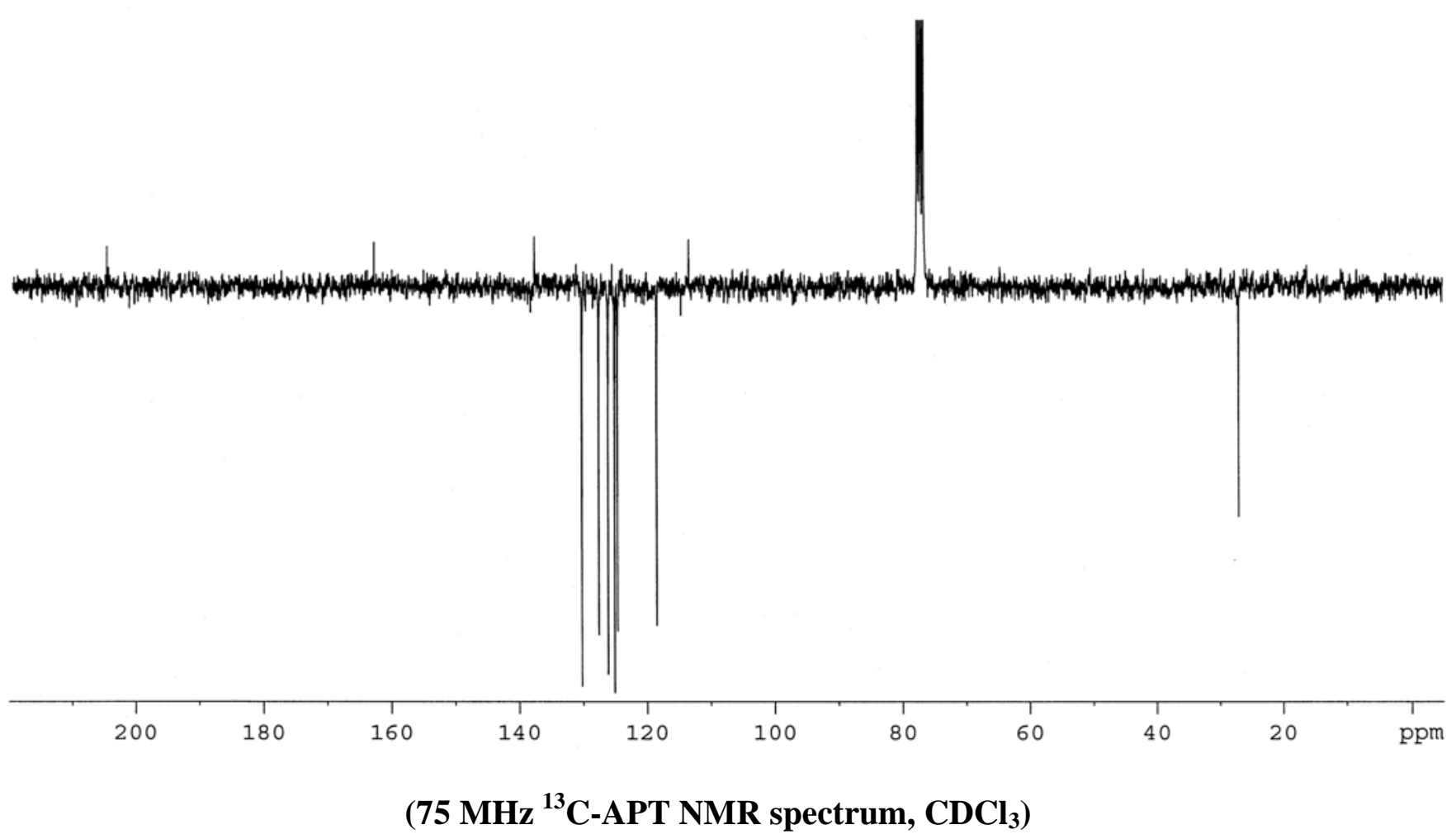




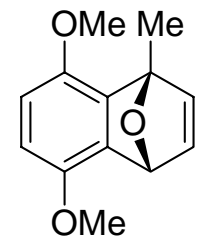

21

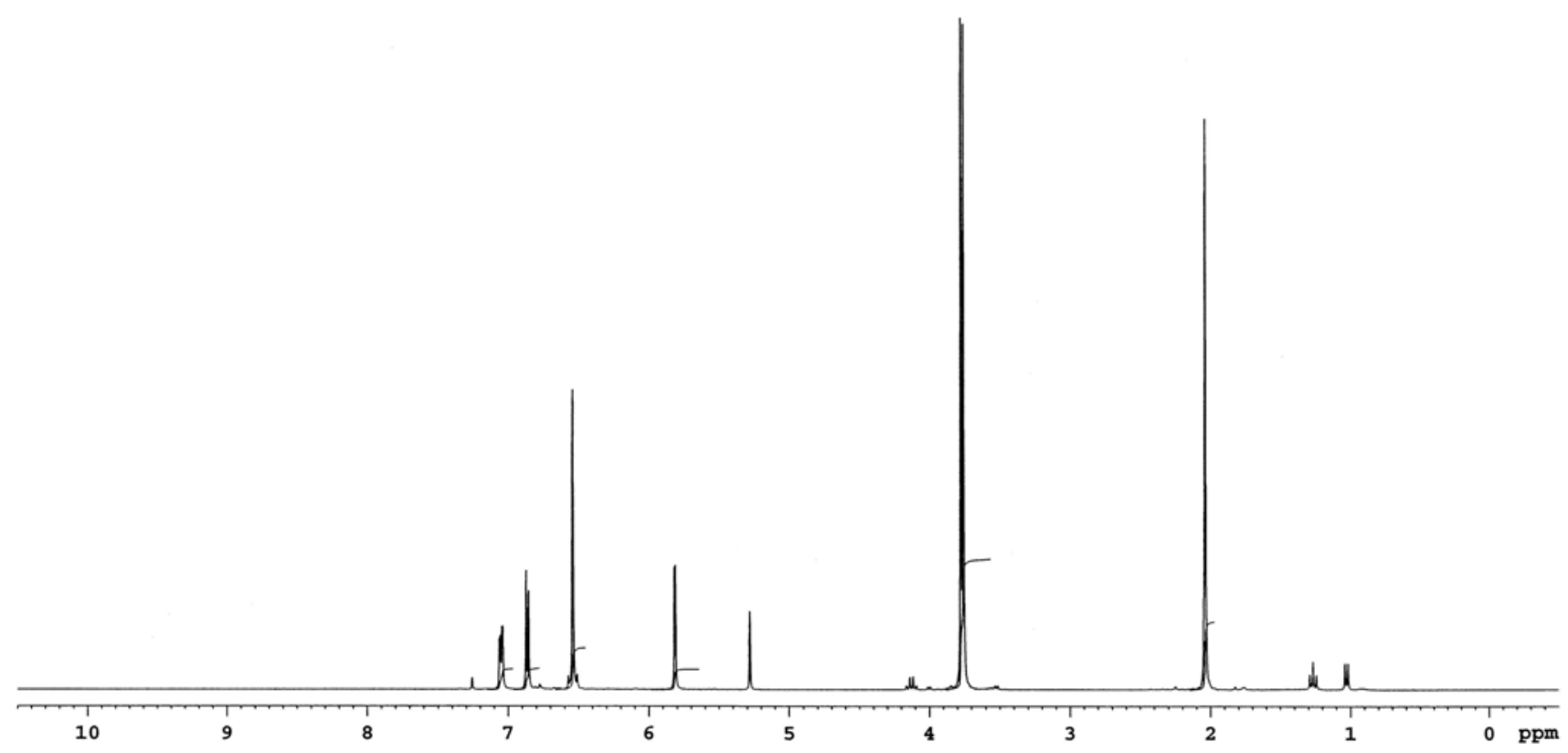

(300 $\mathrm{MHz}^{1} \mathrm{H}$ NMR spectrum, $\mathrm{CDCl}_{3}$ )

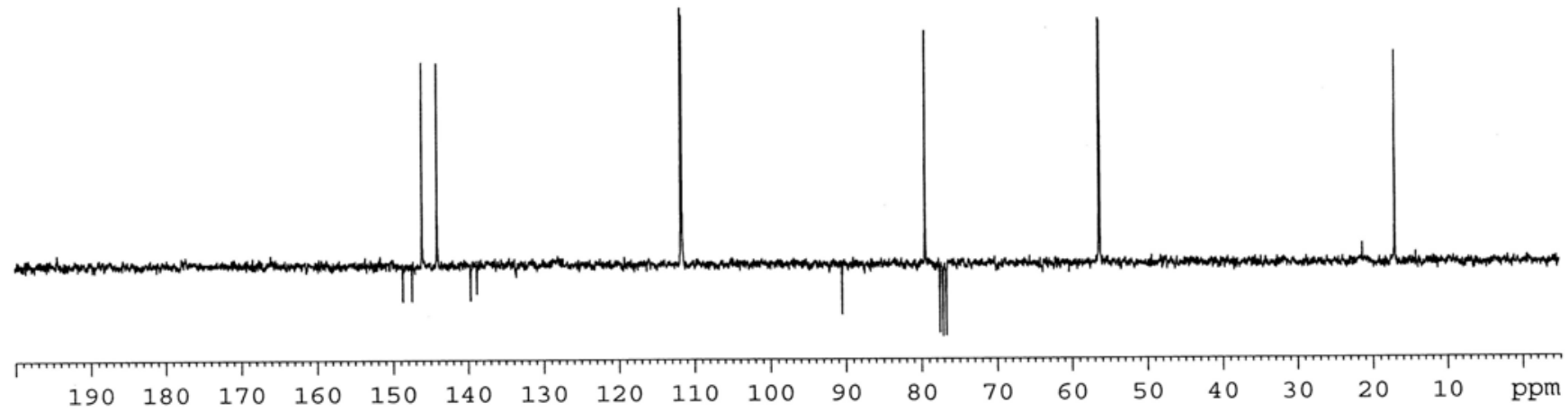

(75 $\mathrm{MHz}{ }^{13} \mathrm{C}$-APT NMR spectrum, $\mathrm{CDCl}_{3}$ ) 
<smiles>COc1ccc(OC)c2c(OC)ccc(O)c12</smiles>

22

(Scheme 9)

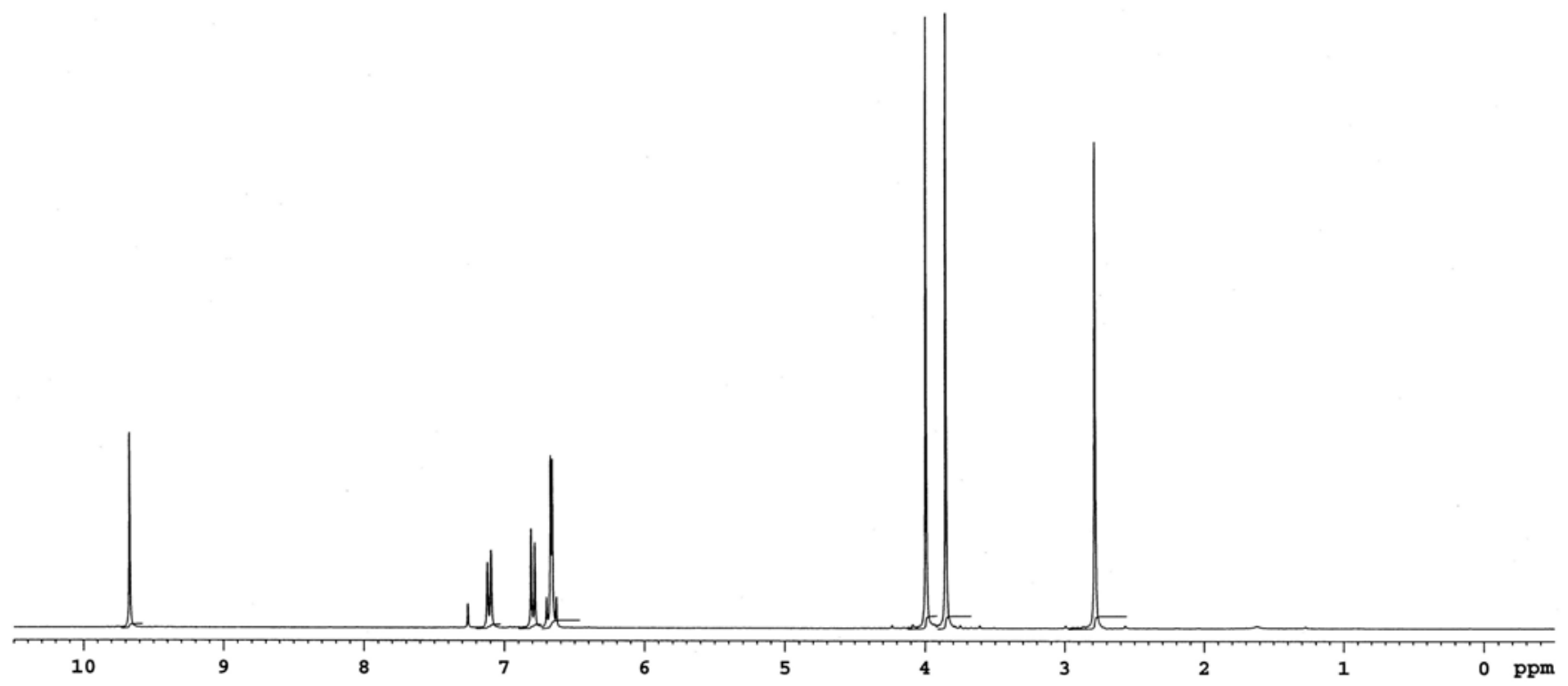

(300 $\mathrm{MHz}^{1} \mathrm{H}$ NMR spectrum, $\mathrm{CDCl}_{3}$ )

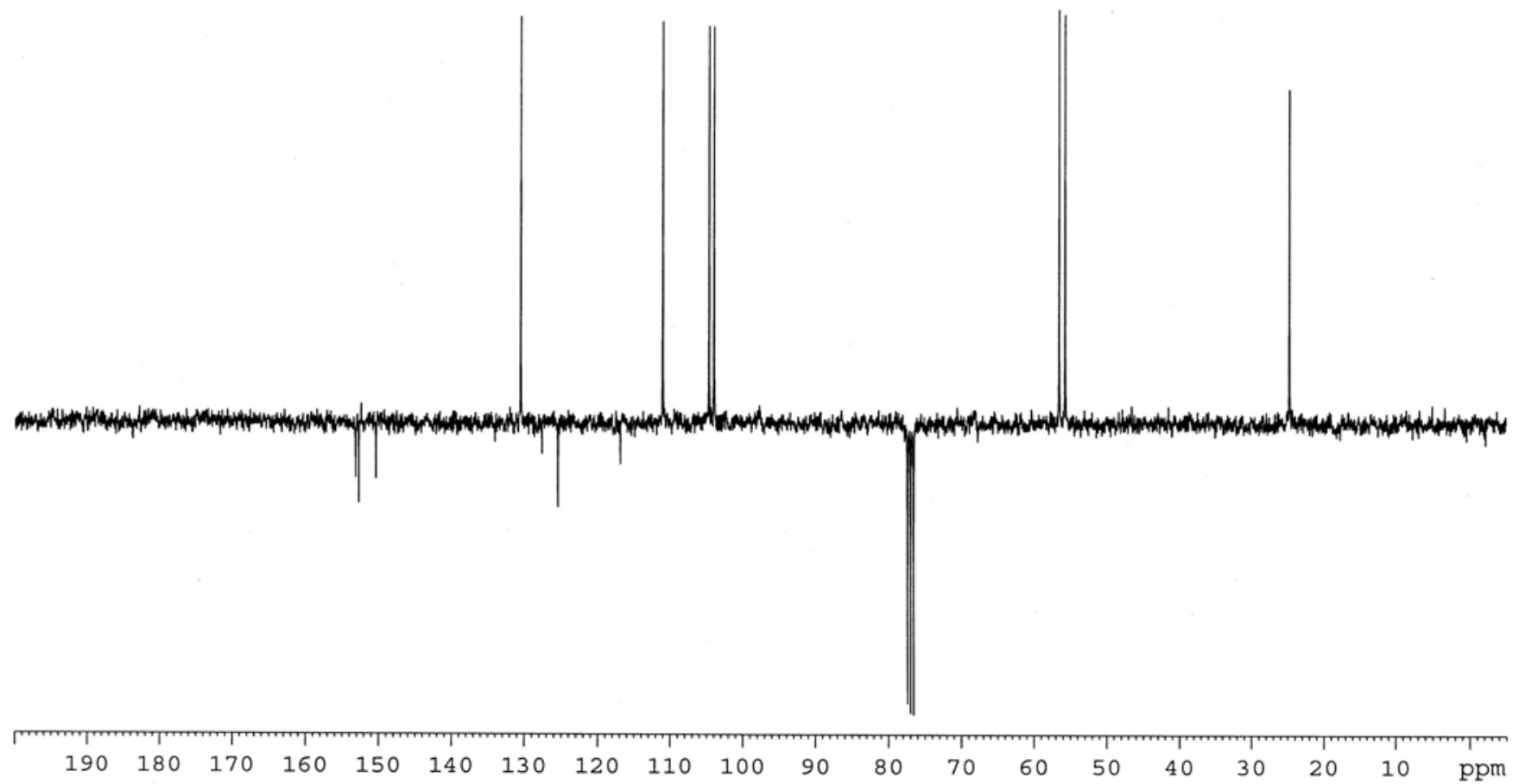

(75 $\mathrm{MHz}^{13} \mathrm{C}$-APT NMR spectrum, $\mathrm{CDCl}_{3}$ ) 
<smiles>COc1ccc(OC)c2c(C)cc(O)cc12</smiles>

23

(Scheme 9)

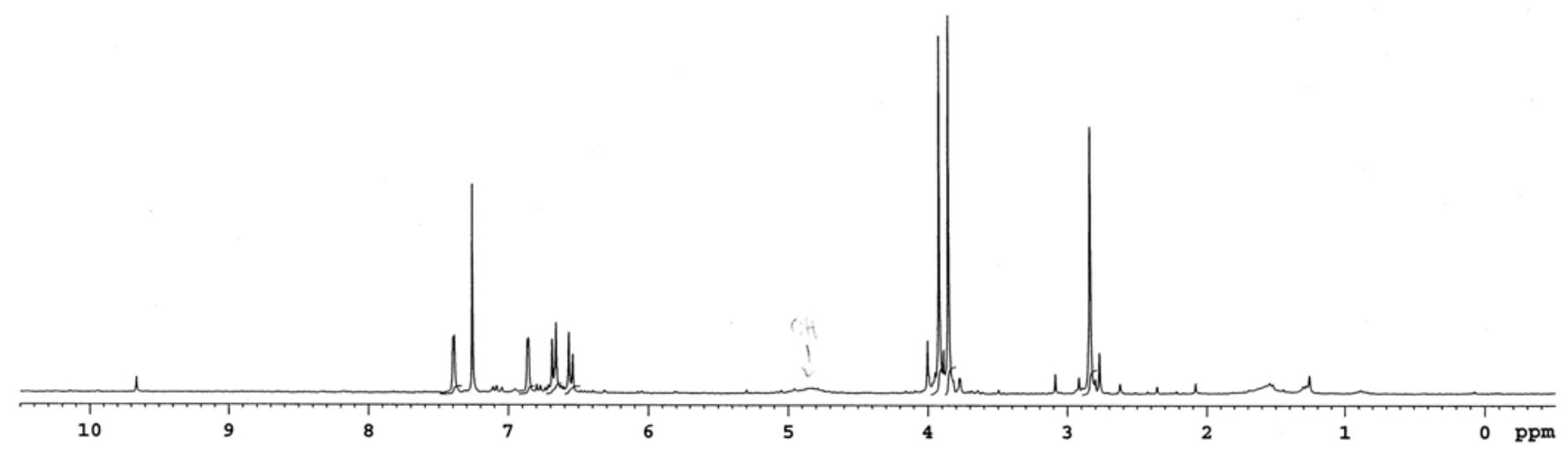

(300 MHz ${ }^{1} \mathrm{H}$ NMR spectrum, $\mathrm{CDCl}_{3}$ )

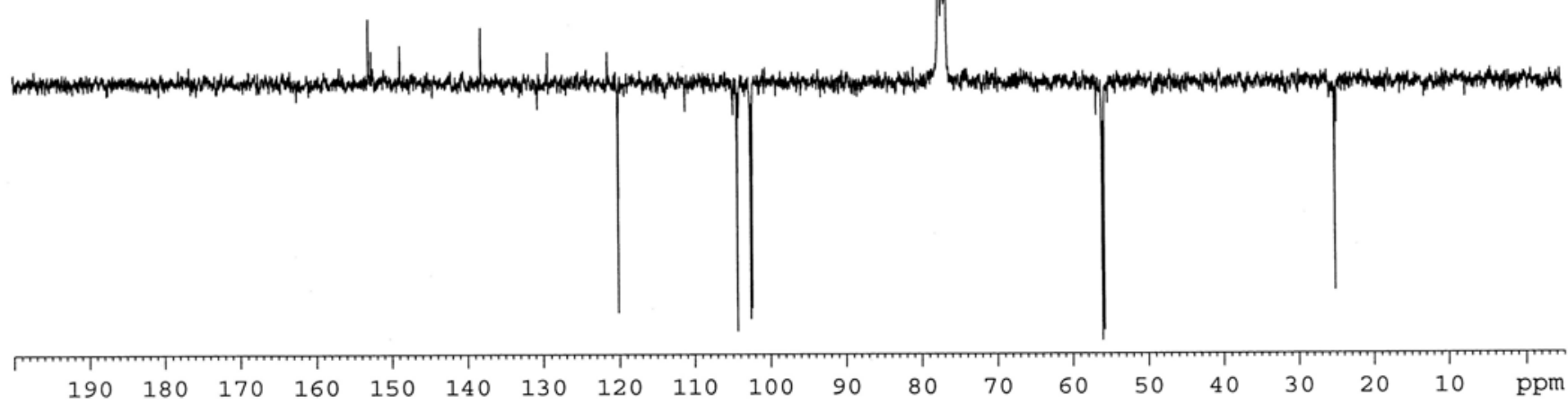

(75 $\mathrm{MHz}^{13} \mathrm{C}$-APT NMR spectrum, $\mathrm{CDCl}_{3}$ ) 
<smiles>COC(=O)c1c(C)ccc(O)c1C(OC)OC</smiles><smiles>CC(=O)c1cc(O)cc(C)c1C(C)=O</smiles>

25b

26b

(Table 9, entry 2)

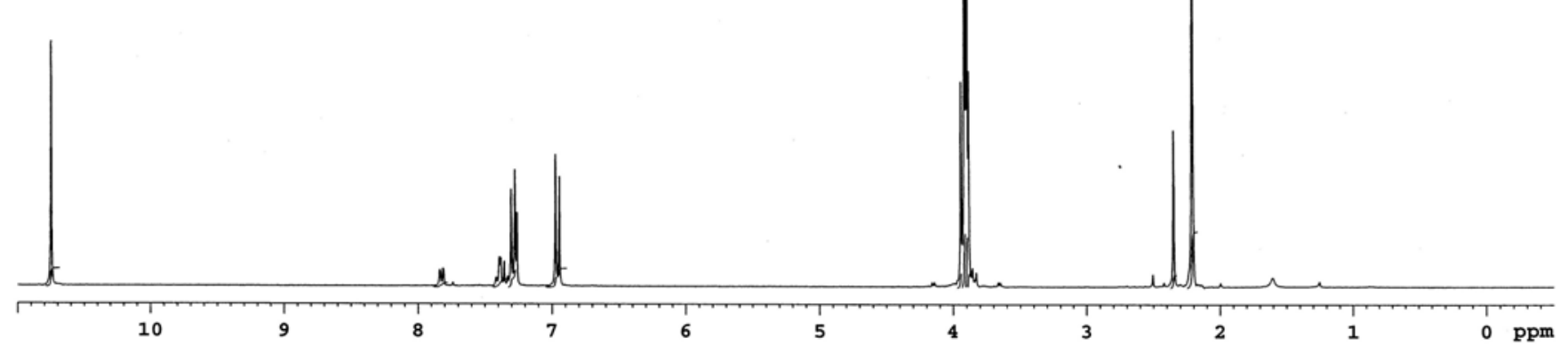

(300 $\mathrm{MHz}^{1} \mathrm{H}$ NMR spectrum, $\mathrm{CDCl}_{3}$ )

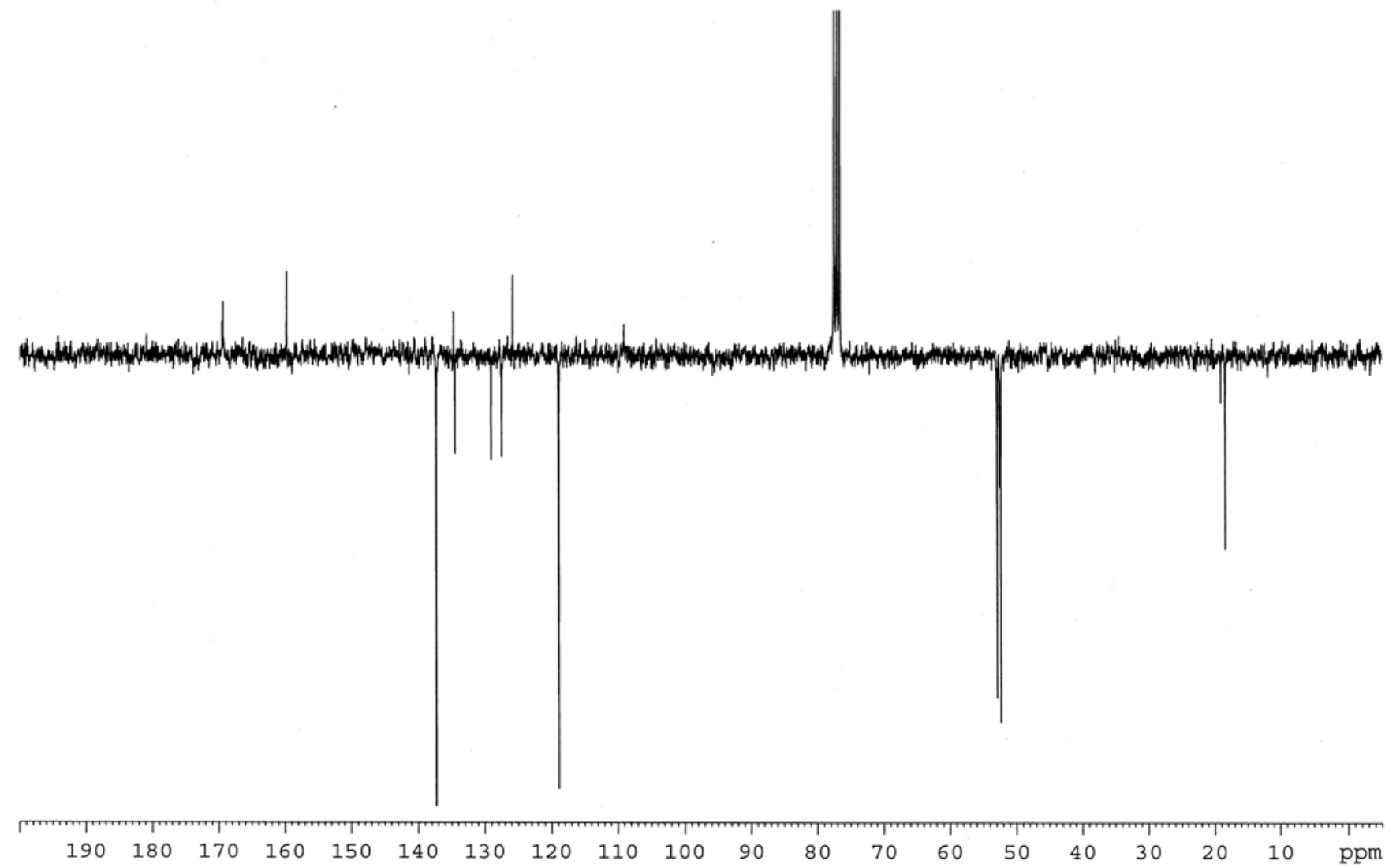

(75 $\mathrm{MHz}^{13} \mathrm{C}$-APT NMR spectrum, $\mathrm{CDCl}_{3}$ ) 

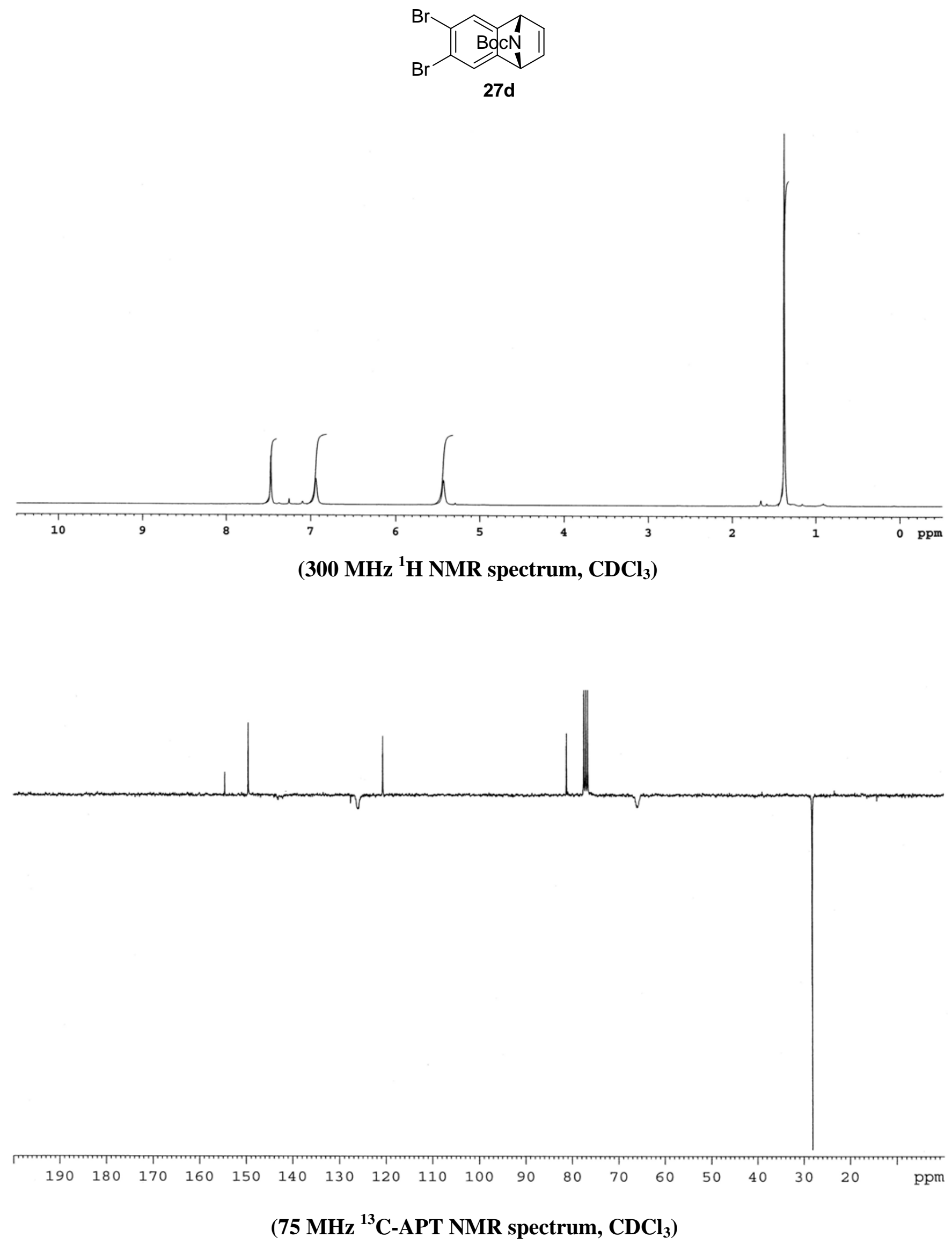


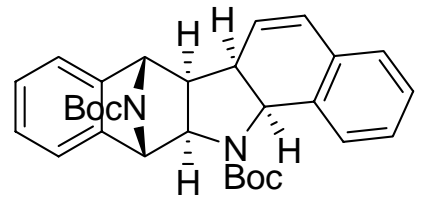

28a

(Table 10, entry 1 )

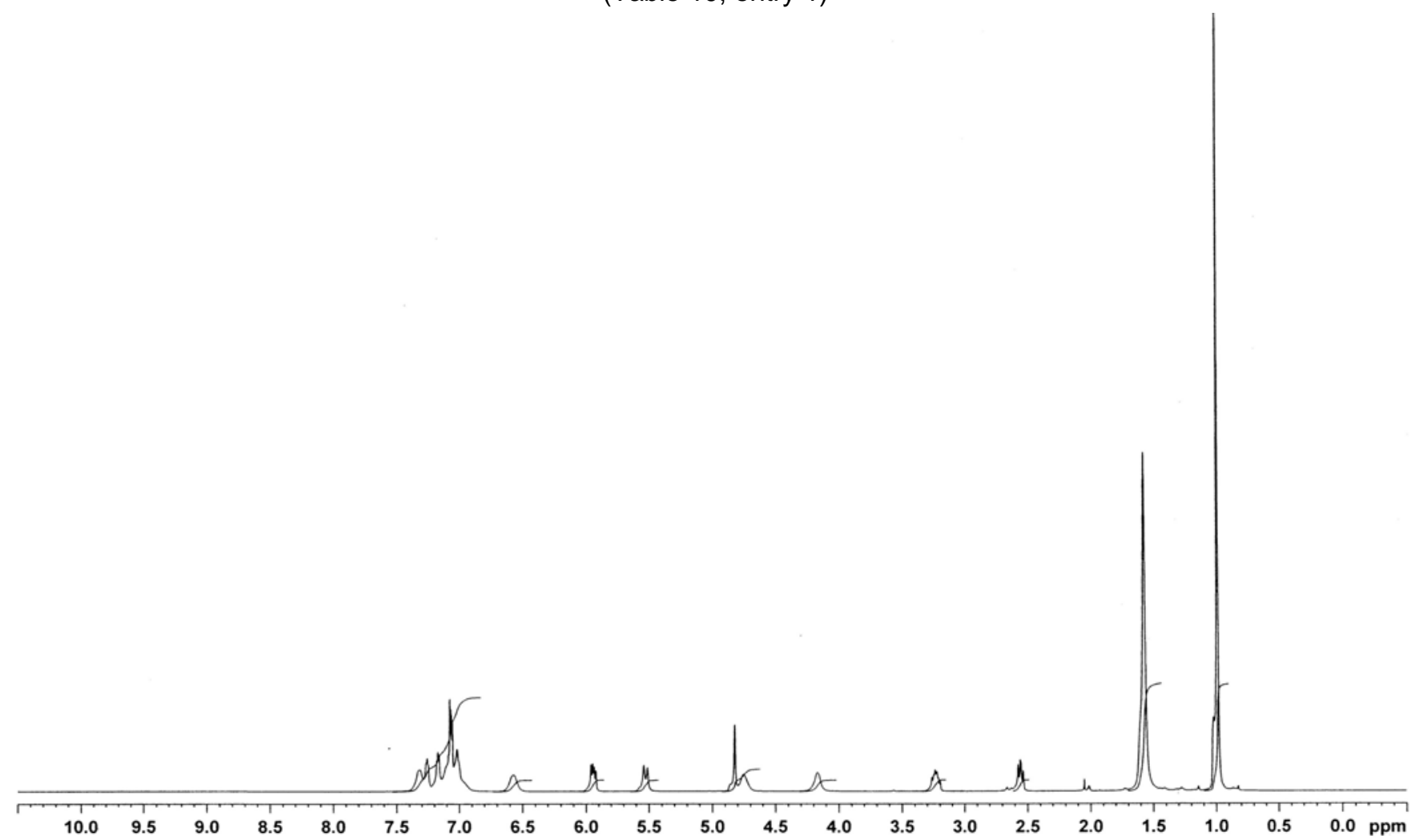

(400 $\mathrm{MHz}^{1} \mathrm{H}$ NMR spectrum, Acetone- $\mathrm{D}_{6}, 40^{\circ} \mathrm{C}$ )

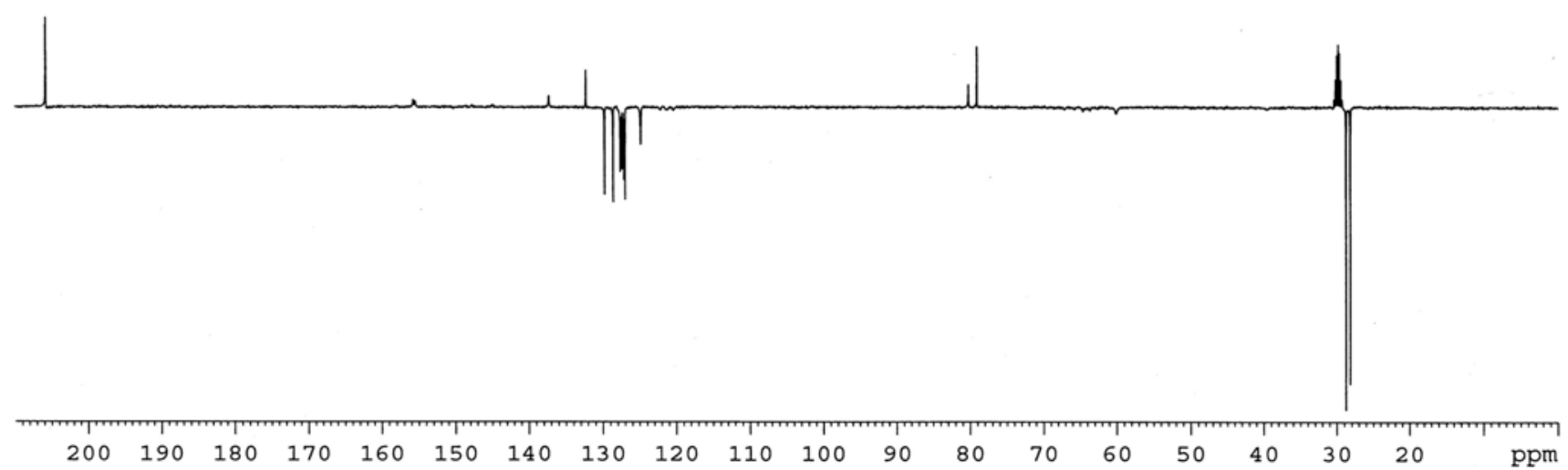

$\left(100 \mathrm{MHz}^{13} \mathrm{C}\right.$-APT NMR spectrum, Acetone- $\mathrm{D}_{6}, 40^{\circ} \mathrm{C}$ ) 


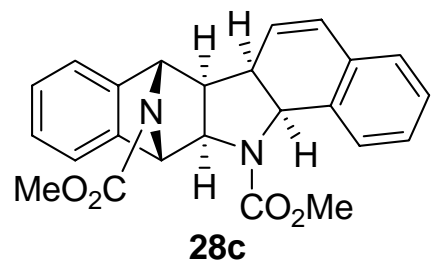

(Table 10, entry 3 )

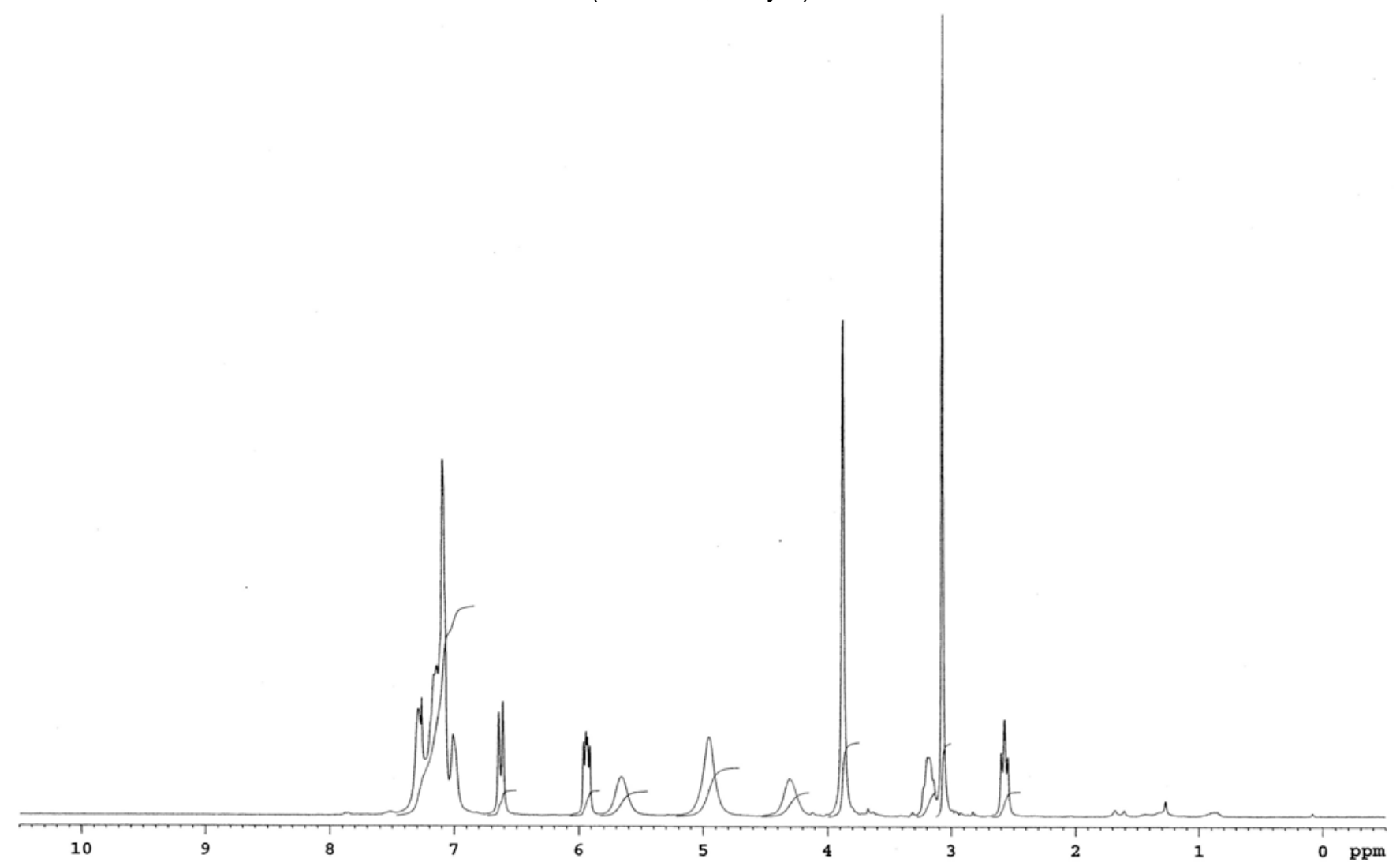

(300 $\mathrm{MHz}^{1} \mathrm{H}$ NMR spectrum, $\mathrm{CDCl}_{3}$ )

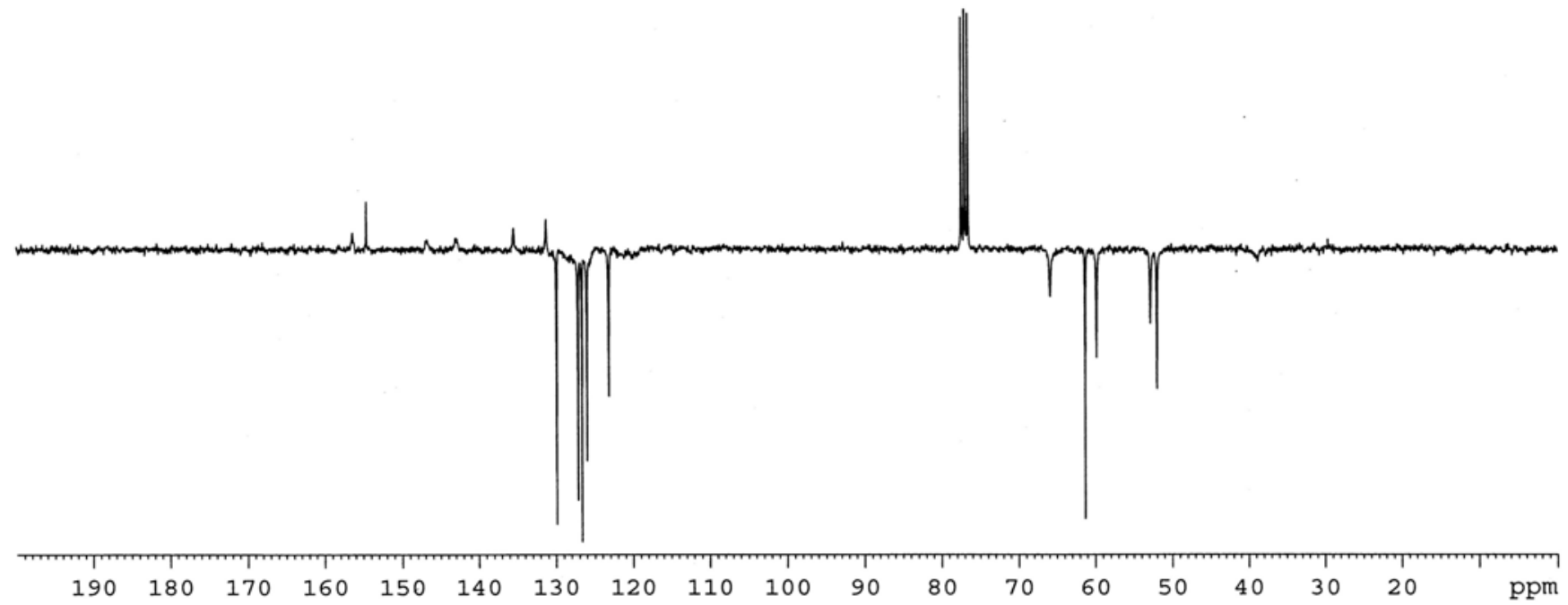

(75 $\mathrm{MHz}^{13} \mathrm{C}$-APT NMR spectrum, $\mathrm{CDCl}_{3}$ ) 


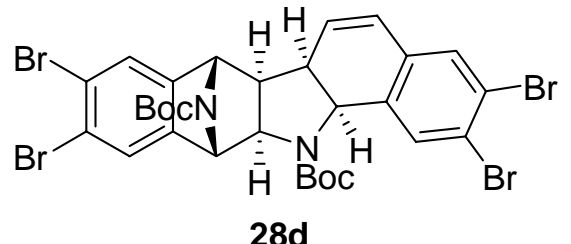

(Table 10 , entry 4 )
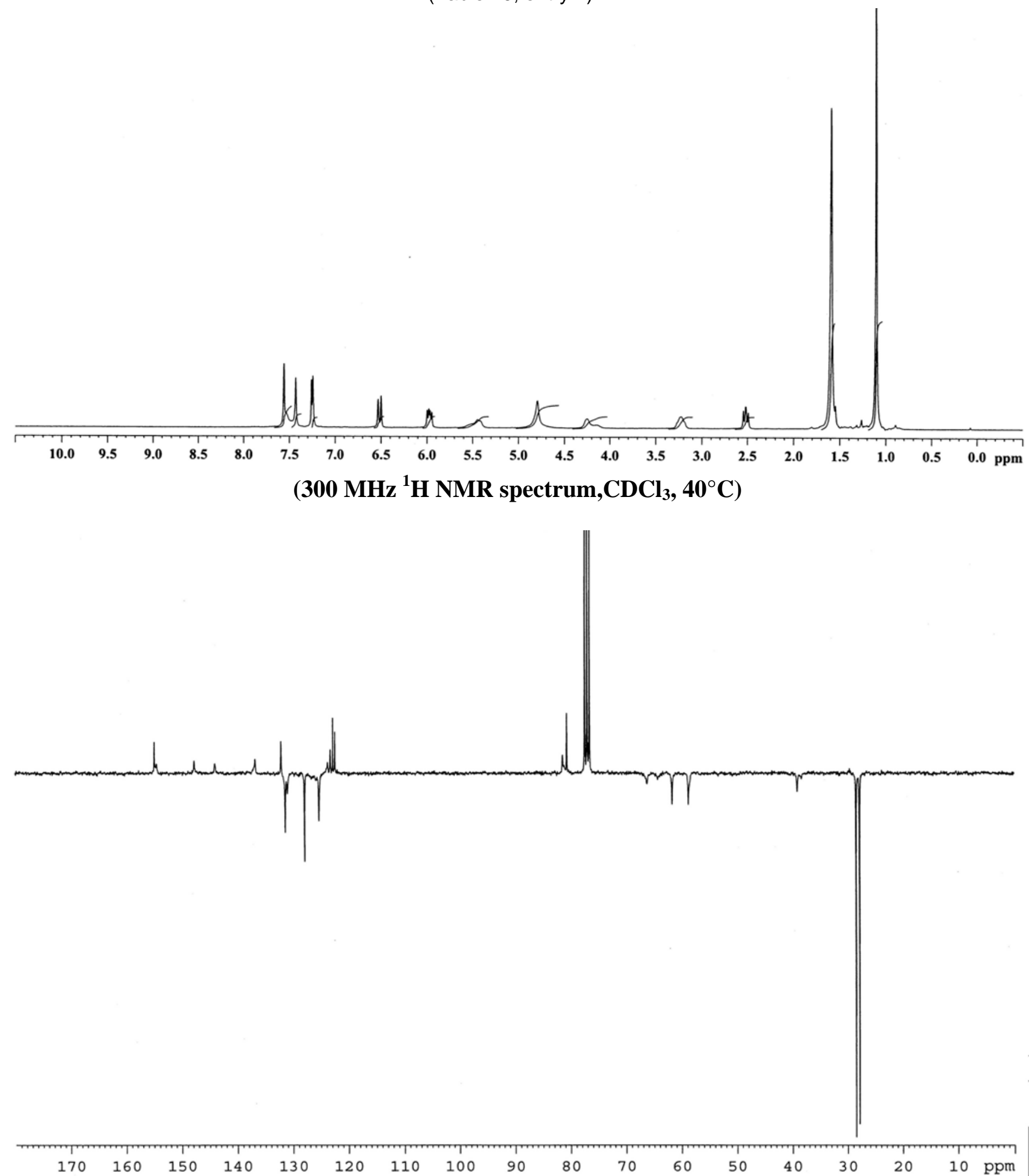
(75 $\mathrm{MHz}^{13} \mathrm{C}$-APT NMR spectrum, $\mathrm{CDCl}_{3}, 4^{\circ} \mathrm{C}$ ) 


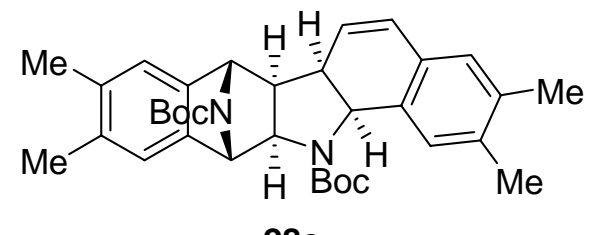

$28 \mathrm{e}$

(Table 10, entry 5)

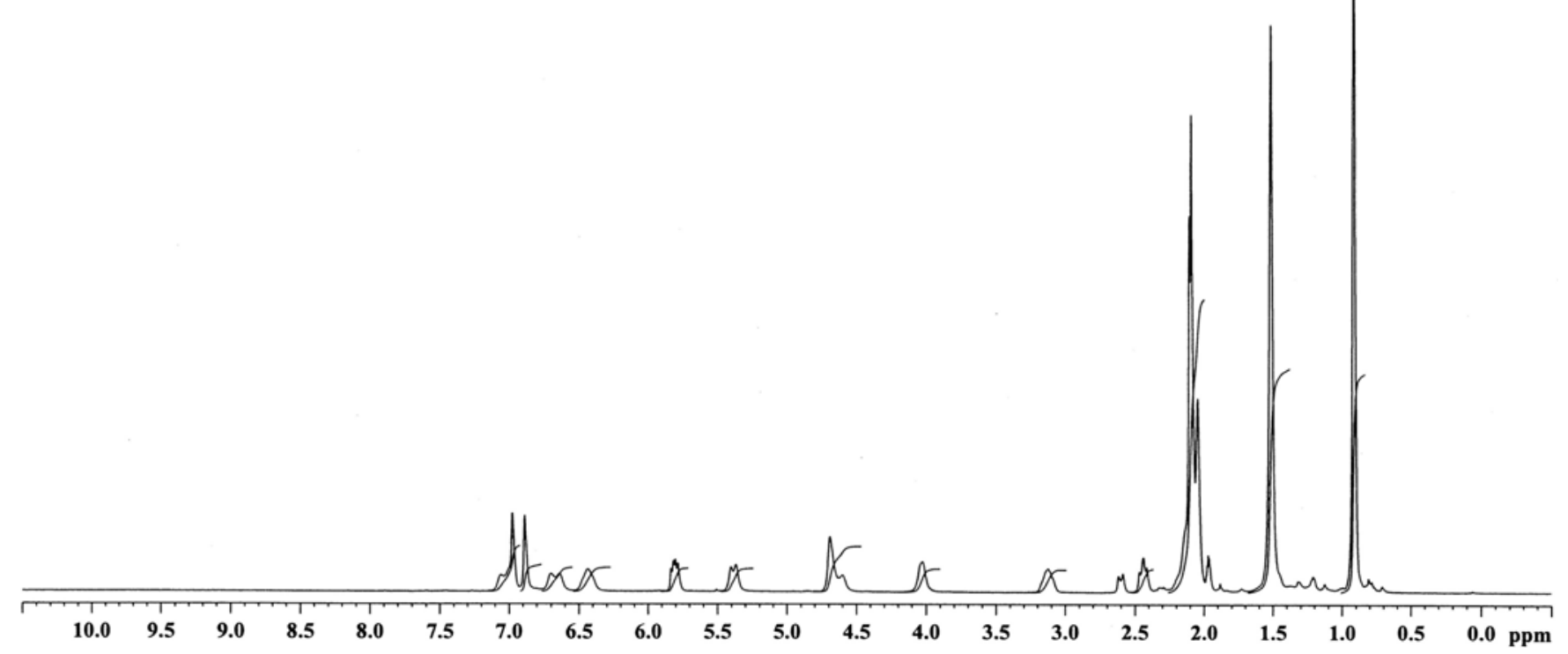

(300 $\mathrm{MHz}{ }^{1} \mathrm{H}$ NMR spectrum, Acetone- $\mathrm{D}_{6}, 40^{\circ} \mathrm{C}$ )

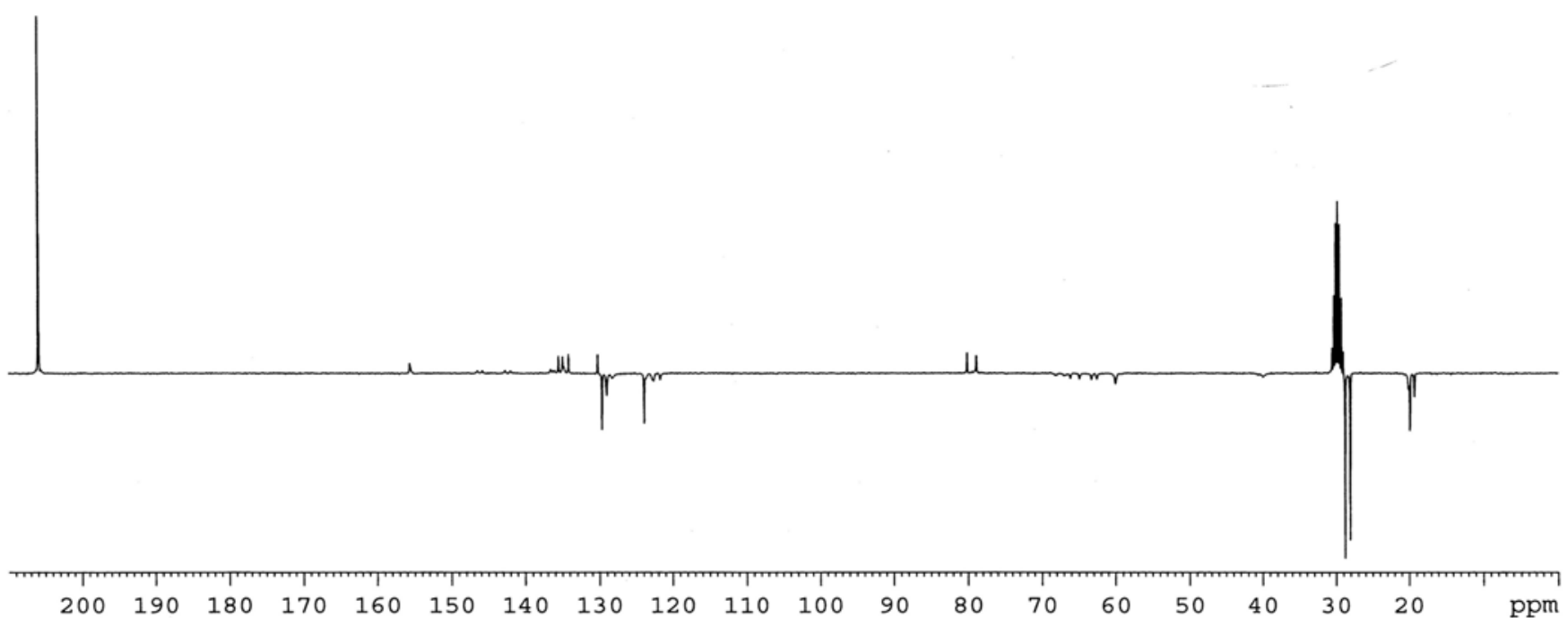

(75 $\mathrm{MHz}^{13} \mathrm{C}$-APT NMR spectrum, Acetone- $\mathrm{D}_{6}, 40^{\circ} \mathrm{C}$ ) 


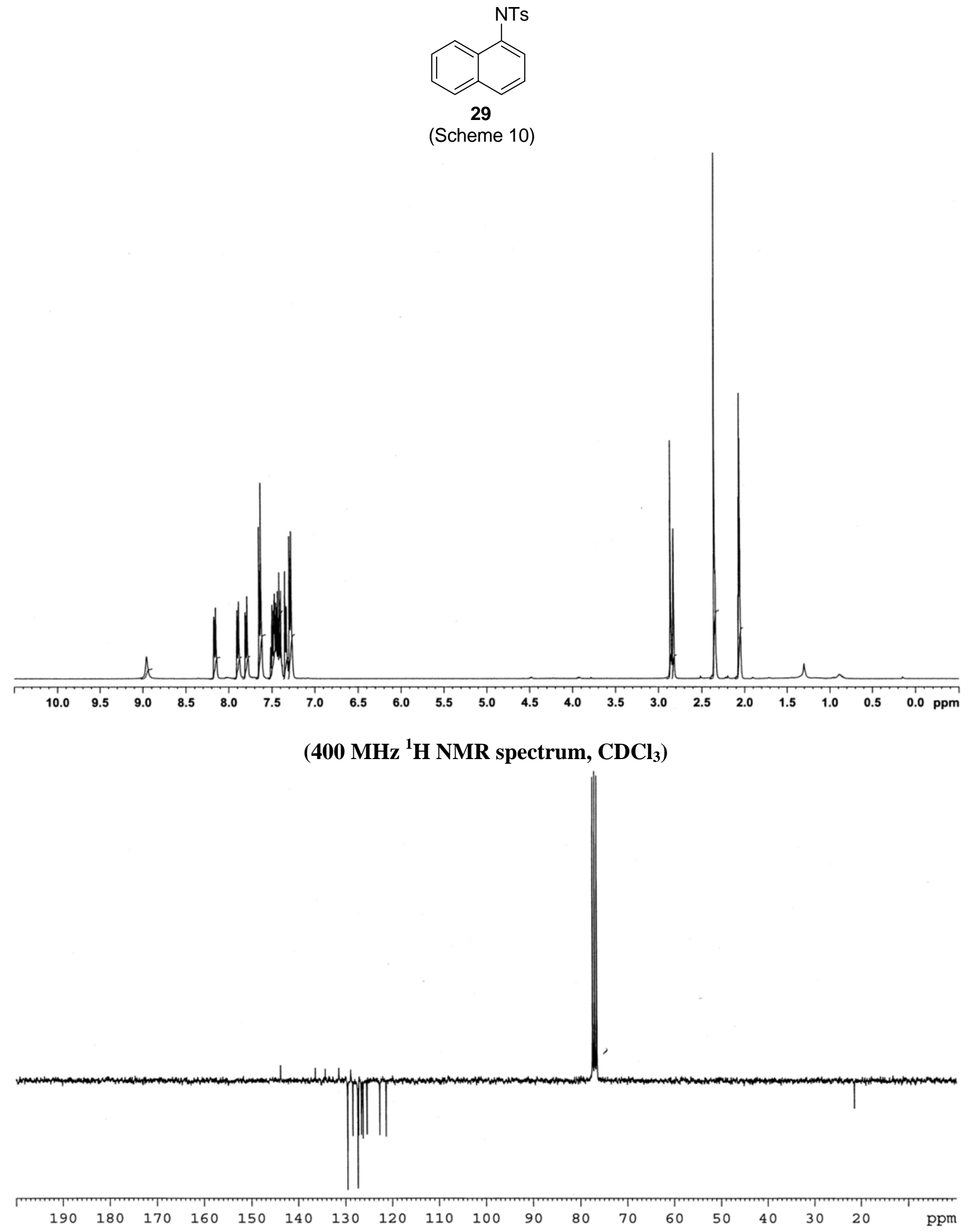

(75 $\mathrm{MHz}^{13} \mathrm{C}$-APT NMR spectrum, $\mathrm{CDCl}_{3}$ ) 